\title{
The Effect of Low Dose Iron and Zinc Intake on Child Micronutrient Status and Development during the First 1000 Days of Life: A Systematic Review and Meta-Analysis
}

\author{
Nicolai Petry ${ }^{1, *,+}$, Ibironke Olofin ${ }^{1, \dagger}$, Erick Boy ${ }^{2}$, Moira Donahue Angel ${ }^{2}$ and Fabian Rohner ${ }^{1}$ \\ 1 GroundWork, Fläsch 7306, Switzerland; ioo523@mail.harvard.edu (I.O.); fabian@groundworkhealth.org (F.R.) \\ 2 Harvest Plus, International Food Policy Research Institute, Washington, DC 20006-1002, USA; \\ E.Boy@cgiar.org (E.B.); m.angel@cgiar.org (M.D.A.) \\ * Correspondence: nico@groundworkhealth.org; Tel.: +41-77-442-9175 \\ + Both authors have contributed equally to the work.
}

Received: 21 September 2016; Accepted: 24 November 2016; Published: 30 November 2016

\begin{abstract}
Adequate supply of micronutrients during the first 1000 days is essential for normal development and healthy life. We aimed to investigate if interventions administering dietary doses up to the recommended nutrient intake (RNI) of iron and zinc within the window from conception to age 2 years have the potential to influence nutritional status and development of children. To address this objective, a systematic review and meta-analysis of randomized and quasi-randomized fortification, biofortification, and supplementation trials in women (pregnant and lactating) and children (6-23 months) delivering iron or zinc in doses up to the recommended nutrient intake (RNI) levels was conducted. Supplying iron or zinc during pregnancy had no effects on birth outcomes. There were limited or no data on the effects of iron/zinc during pregnancy and lactation on child iron/zinc status, growth, morbidity, and psychomotor and mental development. Delivering up to $15 \mathrm{mg}$ iron/day during infancy increased mean hemoglobin by $4 \mathrm{~g} / \mathrm{L}(p<0.001)$ and mean serum ferritin concentration by $17.6 \mu \mathrm{g} / \mathrm{L}(p<0.001)$ and reduced the risk for anemia by $41 \%$ $(p<0.001)$, iron deficiency by $78 \%$ (ID; $p<0.001$ ) and iron deficiency anemia by $80 \%$ (IDA; $p<0.001$ ), but had no effect on growth or psychomotor development. Providing up to $10 \mathrm{mg}$ of additional zinc during infancy increased plasma zinc concentration by $2.03 \mu \mathrm{mol} / \mathrm{L}(p<0.001)$ and reduced the risk of zinc deficiency by $47 \%$ ( $p<0.001)$. Further, we observed positive effects on child weight for age $z$-score (WAZ) $(p<0.05)$, weight for height $z$-score (WHZ) $(p<0.05)$, but not on height for age $z$-score (HAZ) or the risk for stunting, wasting, and underweight. There are no studies covering the full 1000 days window and the effects of iron and zinc delivered during pregnancy and lactation on child outcomes are ambiguous, but low dose daily iron and zinc use during 6-23 months of age has a positive effect on child iron and zinc status.
\end{abstract}

Keywords: Iron; zinc; iron status; zinc status; 1000 days window; infant and young child nutrition; fortification; biofortification

\section{Introduction}

Globally iron and zinc deficiencies are among the most widespread micronutrient deficiencies. While people of all ages are at risk, children and women of reproductive age are at elevated risk of experiencing concurrent deficiencies, especially in low-income countries [1,2]. Even mild deficiencies of one or both nutrients may contribute to increased morbidity and mortality [1]. The first 1000 days of life-the period from conception to the child's 2nd birthday-are most crucial, since some developmental and functional delays during this period are either irreversible or only 
partly reversible [3]. In utero exposure to iron deficiency has been associated with impaired brain maturation of the fetus [4,5], while during infancy and childhood, iron deficiency could lead to impaired cognitive and physical functionality and increased risk of mortality $[1,6]$. Zinc is essential for cellular differentiation and maturation and maternal zinc deficiency could lead to growth retardation and other developmental defects of the fetus [7]. Further, zinc deficient infants and young children are prone to infections and growth retardation [8].

The major cause of micronutrient malnutrition is a diet consisting mainly of staple foods and lacking in animal sources [9]. When compounded by exposure to environments laden with pathogens, there is a synergistic worsening of the malnutrition burden [10,11]. Although high dose supplementation has been successful in reducing the prevalence of micronutrient deficiencies, programs often only inadequately reach rural or marginalized populations; also high dose iron supplementation has been exposed to criticism in the past decade in malaria endemic areas [12]. Other interventions such as fortification and biofortification, delivering smaller amounts of micronutrients on a daily basis, might be more effective in reducing the prevalence of micronutrient deficiencies in populations at risk; yet, their effect on the infant during the first 1000 days of life starting from pregnancy until 23 months of age has hardly been investigated.

The objective of this work was thus to evaluate the potential of interventions delivering daily doses of iron and zinc in concentrations up to approximately the Recommended Nutrient Intake (RNI) in diets with low bioavailability [1] during the first 1000 days of life on child micronutrient status and health.

For this we used data from randomized and quasi-randomized trials of fortification, supplementation or biofortification interventions, in which iron and zinc were provided more than three times a week in concentrations up to approximately the (RNI) for women (iron: $45 \mathrm{mg}$ /day; zinc $20 \mathrm{mg} /$ day) and children 6-23 months (iron: $15 \mathrm{mg} /$ day; zinc: $10 \mathrm{mg} /$ day).

\section{Materials and Methods}

\subsection{Search Strategy}

We searched the WHO e-Library of Evidence for Nutrition Actions, the Cochrane Central library, Web of Science, and MEDLINE/PUBMED databases to identify systematic reviews and meta-analyses that investigated the effects of iron and zinc interventions (fortification, supplementation, or biofortification interventions) on nutritional, developmental and health outcomes of children. We restricted the search to reviews published from 2005 to 2015. The following search strategy was adapted for each database: (Fortification OR biofortification OR supplementation) AND (iron OR zinc OR multiple micronutrients OR micronutrient powder) AND (women OR children OR infants OR toddlers). For the relevant topics, 82 potentially useful reviews and meta-analyses published from 2005 to 2015 were identified, the most recent ones conducting their literature searches up until 2014. We searched their reference lists for suitable original studies. Additional searches for original studies published between 2011 and October 2015 were conducted in Web of Science and MEDLINE/PubMed using the following strategies for each age group of interest:

(a) Children: (Biofortification OR fortification OR supplementation) AND (iron OR zinc OR micronutrient powder OR multiple micronutrients) AND (children OR infants OR toddlers) AND (trial OR study OR survey OR assessment).

(b) Pregnant women: (Biofortification OR fortification OR supplementation) AND (pregnant women OR lactating women OR maternal) AND (iron OR zinc OR micronutrient powder OR multiple micronutrients) AND (trial OR study OR survey OR assessment).

(c) Lactating women: (Biofortification OR fortification OR supplementation) AND lactating women AND (zinc OR iron OR micronutrient powder OR multiple micronutrients OR breast milk) AND (trial OR study OR survey OR assessment). 


\subsection{Inclusion and Exclusion Criteria}

Types of trials and interventions: Randomized controlled trials (RCTs) and quasi-experimental studies were included in the review. Studies were eligible if they assessed the impact of iron or zinc supplementation, fortification or biofortification interventions on the micronutrient status, growth or health outcomes of children (details below). Only studies where the daily iron and zinc dose did not exceed $15 \mathrm{mg}$ and $10 \mathrm{mg}$, respectively for children and $45 \mathrm{mg}$ and $21 \mathrm{mg}$, respectively for women, were included. We considered micronutrient powders and crushable tablets (foodlets) as fortification, since they are consumed as part of a normal meal. Furthermore, we included studies investigating the effects of iron or zinc supplements, as long as they were within the dose range we specified. We defined supplements as compounds, which are routinely consumed separately from a normal meal, including tablets, pills, drops, capsules, syrups, drinks, biscuits, and lipid-based supplement (LNS). Only studies administering the micronutrients $>3$ times a week were included.

Types of participants: For interventions administered to the mother, we included studies that provided interventions to pregnant women or lactating women, regardless of their health status. For interventions administered to children, we were interested in effects on young children, thus only studies where over $50 \%$ of participating children were 6-23 months old were included. Only studies involving apparently healthy children were considered, with the exception that studies including malnourished (underweight, stunted, wasted) children and children suffering from anemia or deficiencies of iron and zinc were included. We did not include therapeutic studies, such as short term zinc supplementation studies to treat acute diarrhea.

\subsection{Study Design and Comparison Groups}

The control groups of the included fortification trials either received unfortified foods or regular diets. Studies were also included if both the control and intervention groups received the same fortified foods, but either with different iron or zinc concentrations, or if the control group received an identical micronutrient compound given to the intervention group, but without iron or zinc. For supplementation, the control groups of the included trials either received no supplements, placebo, a lower concentration of iron or zinc or different micronutrients identical to intervention group preparations, except that they excluded zinc and/or iron.

Studies were only included in meta-analyses if the data for outcomes of interest were presented in a manner that allowed inclusion in the meta-analysis (i.e., data could only be used when presented as mean (SD or SE), mean (95\% CI), median (95\% CI), or median (range), but not when reported as median (IQR)). Where studies did not report on the average daily micronutrient intake, but instead stated the micronutrient concentration per $100 \mathrm{~mL} / 100 \mathrm{~g}$ or the daily micronutrient intake in $\mathrm{mg} / \mathrm{kg}$ body weight, we calculated the average intake as appropriate.

\subsection{Outcome Measures}

Only child outcomes were of interest, even when interventions were administered to pregnant or lactating women. For example, with regard to effects of prenatal iron supplementation on anemia, maternal anemia was not the focus of this analysis; rather, the infant/child anemia was of relevance even if the mother received the intervention.

Outcomes evaluated include: (1) hemoglobin $(\mathrm{Hb})$ concentration $(\mathrm{g} / \mathrm{dL}) ;(2)$ anemia $(\%$; defined as $\mathrm{Hb}<110 \mathrm{~g} / \mathrm{L})$; (3) serum ferritin concentration ( $\mu \mathrm{g} / \mathrm{L})$; (4) iron deficiency (\%; defined as serum ferritin $<10 \mu \mathrm{g} / \mathrm{L}$ or $<12 \mu \mathrm{g} / \mathrm{L}$ ); (5) iron deficiency anemia (\%; defined as $\mathrm{hb}<105 \mathrm{~g} / \mathrm{L}$ or $<110 \mathrm{~g} / \mathrm{L}$ and serum ferritin $<10 \mu \mathrm{g} / \mathrm{L}$ or $<12 \mu \mathrm{g} / \mathrm{L})$; (6) serum or plasma zinc ( $\mu \mathrm{mol} / \mathrm{L})$; (7) zinc deficiency (\%; defined as serum zinc $<10.7 \mu \mathrm{mol} / \mathrm{L}$ ); (8) birth outcomes (birth weight in g; prevalence of low birth weight in \%, defined as weight $<2500 \mathrm{~g}$ ); (9) infant anthropometric measures (height for age z-score (HAZ); weight for age $z$-score (WAZ); weight for height $z$-score (WHZ); stunting ( $\leq-2$ HAZ scores), wasting $(\leq-2$ WHZ scores) underweight ( $\leq-2$ WAZ scores)); (10) mental and motor development (Bayley 
mental development index (MDI); Bayley psychomotor development index (PDI)); (11) morbidity (diarrhea, fever and respiratory infection).

\subsection{Data Synthesis and Statistical Analysis}

From each eligible study, we extracted all data that would allow the estimation of the effects of interest. For example, for zinc studies, data were extracted for groups assigned to zinc alone compared with placebo, as well as data from groups assigned to more than one nutrient including zinc compared with a group assigned to the identical nutrient combination but excluding zinc. Where the total number of comparisons was sufficiently large, we examined the influence of combining such comparisons into one meta-analysis, and where possible, conducted sub-group analyses examining the possibility of nutrient interactions. Additionally, where studies had more than one group assigned to the nutrient of interest (for instance, different nutrient dosages) but only one suitable comparison group, we included such data as separate estimates for the meta-analysis. For that, we divided the comparison group into two groups (or more, when required) with smaller sample sizes, so the same children were not involved in more than one comparison. To examine if this decision affected the results, we conducted sensitivity analyses combining all relevant control groups of affected studies into a single comparison group, and combining all relevant intervention groups into a single group, for some outcomes. As results were very similar, we chose to continue analyses with the sub-groups. When studies reported outcomes at multiple time points, we selected only the results reported at the study end (or the latest time point) for the meta-analyses. Most studies were individually randomized trials, but where cluster randomized trials were eligible for inclusion, we estimated design effects to adjust for the influence of intra-cluster correlations on the precision of estimates as appropriate. To maximize the number of studies that could contribute to meta-analyses of continuous outcomes, we converted medians (reported with ranges) and geometric means (reported with standard deviations, standard errors or confidence intervals) to arithmetic means and standard deviations using methods developed by Hozo et al. [13] and Higgins et al. [14] and examined the effect that combining transformed and untransformed estimates had on pooled results. Studies were excluded from meta-analyses if published reports presented insufficient information for estimating desired effect estimates and variances.

For continuous outcomes, we estimated pooled mean differences or standardized mean differences and confidence intervals, as appropriate, while for categorical outcomes, we estimated pooled risk ratios and confidence intervals. Study-level effect estimates were pooled using the random effects meta-analysis method by DerSimonian and Laird [15]. We assessed heterogeneity among studies, and used the method proposed by Higgins et al. to measure the inconsistency $\left(I^{2}\right)$ of effect estimates across studies [16]. Heterogeneity among study estimates was considered to be substantial if the $I^{2}$ exceeded $50 \%$. For outcomes having at least 10 comparisons per variable of interest, we explored sources of heterogeneity by conducting pre-specified sub-group analyses and meta-regressions, to examine whether effects were modified by the study-level factors: micronutrient doses provided, type of intervention (whether fortification or supplementation), study quality and baseline micronutrient status. Funnel plots were constructed for visual assessment of the variability of individual study estimates and to evaluate the possibility of publication bias, and when appropriate, Egger's tests were used to examine if effect estimates varied with study sample size.

All analyses were conducted using the metafor package [17] of the $\mathrm{R}$ statistical program (R version 3.1.3 (2015-03-09), The R Foundation, Vienna, Austria, 2015).

\subsection{Assessment of Quality and Risk of Bias}

We assessed study quality in three areas-random sequence generation, adequacy of blinding of study participants and personnel and completeness of outcomes assessment-but did not exclude studies based on the assessment of quality. Studies were categorized as being of the 'highest quality' if interventions were randomly assigned, both participants and study personnel were adequately blinded to the intervention assignment, and if outcomes were assessed in at least $75 \%$ of the enrolled study population. Intermediate quality trials were randomized trials for which only one of the remaining 
two criteria was suboptimal, lowest quality trials were randomized trials for which both the remaining criteria were suboptimal, and quasi-experimental trials (although rarely included) were given the very lowest rating. The effect of pooling results from studies of different quality was examined in sub-group analyses where possible.

The quality of the evidence resulting from each analysis was assessed using the Grading of Recommendations Assessment, Development, and Evaluation (GRADE) method [18]. Domains included: risk of bias within studies (internal validity), inconsistency or heterogeneity of results across studies, indirectness or use of proxy populations, interventions or outcomes measures, imprecision (large variability and wide confidence intervals), number of studies and risk of publication bias. The evidence was judged as high quality if further research studies were unlikely to change the pooled estimate obtained; moderate quality if further research could alter the current estimate; low quality if further research was needed to confirm the magnitude and direction of the true effect; and very low quality if there was great uncertainty about the validity of the pooled estimate. It should be noted that because the GRADE method considers several domains and not just internal study validity, confidence in pooled estimates could be 'low' or 'very low' even if all studies that contributed to the estimate were well conducted.

\section{Results}

\subsection{Literature Search}

We identified and screened 4542 records, reviewed 326 full-texts for eligibility and finally included 90 studies in the review (Figure S1). Identified studies were supplementation or fortification studies-no biofortification studies qualified for inclusion. Thirty-three iron intervention studies and 47 zinc intervention studies involving children 6-23 months old met our inclusion criteria. Of the prenatal intervention studies that reported child outcomes, seven iron studies and 10 zinc studies met our inclusion criteria. Additionally, we identified one eligible study that delivered zinc to lactating women. The major reasons for excluding studies were: (a) micronutrient doses higher than our selected threshold; (b) ineligible ages, e.g., more than half of participating children over 23 months old and (c) dosing frequencies less than our threshold.

\subsection{Effects of Low-Dose Iron Interventions during Pregnancy and Lactation on Child Outcomes}

Six studies reported birth weights of infants [19-24] while five studies reported on the effects of iron on the prevalence of low birth weight (Table 1; [19,21-24]). Exclusively supplementation trials contributed to the analyses, delivering daily 18-30 mg of iron. We found that low dose iron interventions during pregnancy do not significantly change birth weights ( $p=0.17$; Figure S2) or the prevalence of low birth weight ( $p=0.23$; Figure S3) among the offspring. We did not identify any studies investigating the effects of prenatal iron interventions on child micronutrient status or child growth within the first two years of life. We identified a study by Li and colleagues [25] that investigated the effects of prenatal iron and folic acid compared with folic acid alone on PDI and MDI scores of children at 3, 6, and 12 months of age. No differences were detected between the iron/folic acid group and the folic acid only group. The main results of the meta-analysis of prenatal iron interventions are summarized in Table 1.

Table 1. Effects of prenatal iron interventions supplying $\leq 45 \mathrm{mg} /$ day iron on birth weight and prevalence of low birth weight among offspring.

\begin{tabular}{|c|c|c|c|c|c|}
\hline Variables & $\begin{array}{c}\text { Mean } \\
\text { Difference }\end{array}$ & Relative Risk & $\begin{array}{c}\text { Studies, } \\
\text { Participants }(n)\end{array}$ & $I^{2}(\%)$ & $\begin{array}{c}p \text { Difference between Pooled } \\
\text { Intervention and Control Groups }\end{array}$ \\
\hline \multicolumn{6}{|c|}{ Birth outcomes } \\
\hline Birthweight (g) & $38(-16 ; 91)$ & & $6,13,627$ & 58.2 & 0.17 \\
\hline Low birth weight (\%) & & $0.69(0.38 ; 1.26)$ & $5,12,845$ & 63.1 & 0.23 \\
\hline
\end{tabular}




\subsection{Iron Interventions in Children 6-23 Months of Age}

The results of meta- analyses of iron intervention studies involving children are presented below and summarized in Tables 2 and 3.

Table 2. Effects of daily iron administration ( $\leq 15 \mathrm{mg}$ /day) to children 6-23 months on levels of hemoglobin, anemia, serum ferritin, iron deficiency, and iron deficiency anemia ${ }^{1}$.

\begin{tabular}{|c|c|c|c|c|c|}
\hline Variables & $\begin{array}{c}\text { Mean } \\
\text { Difference }{ }^{2}\end{array}$ & Relative Risk & $\begin{array}{c}\text { Studies, } \\
\text { Participants }(n)\end{array}$ & $I^{2}(\%)$ & $\begin{array}{l}p \text { Difference between Pooled } \\
\text { Intervention and Control } \\
\text { Groups (Bold Font) and } \\
\text { Subgroups (Regular Font) }\end{array}$ \\
\hline Hb overall (g/dL) & $4.1(2.8 ; 5.3)$ & & 30,6569 & 81.5 & $<0.001$ \\
\hline \multicolumn{6}{|c|}{ Iron dose } \\
\hline$<6 \mathrm{mg} /$ day & $-0.7(-6.1 ; 4.7)$ & & 2,220 & 73.1 & \multirow{4}{*}{0.12} \\
\hline $6-8 \mathrm{mg} /$ day & $4.4(2.1 ; 6.8)$ & & 7,1864 & 83.9 & \\
\hline$>8-10 \mathrm{mg} /$ day & $5.5(3.4 ; 7.6)$ & & 13,3068 & 83.8 & \\
\hline $11-15 \mathrm{mg} /$ day & $2.7(1.2 ; 4.2)$ & & 4,403 & 80.7 & \\
\hline \multicolumn{6}{|c|}{ Type of intervention } \\
\hline Supplementation & $5.6(3.4 ; 7.7)$ & & 15,3516 & 86.4 & \multirow{2}{*}{$<0.01$} \\
\hline Fortification ${ }^{3}$ & $2.6(1.3 ; 3.9)$ & & 16,3053 & 67.4 & \\
\hline \multicolumn{6}{|c|}{$\mathrm{RCT}$, quality rating } \\
\hline highest & $5.5(3.3 ; 7.6)$ & & 12,3403 & 87.1 & \multirow{3}{*}{$<0.05$} \\
\hline intermediate & $3.2(1.6 ; 4.8)$ & & 14,2623 & 73.1 & \\
\hline lowest & $1.3(-2.9 ; 5.4)$ & & 4,375 & 80.3 & \\
\hline Anemia overall & & $0.59(0.49 ; 0.70)$ & $22,(5647)$ & 73.8 & $<0.0001$ \\
\hline \multicolumn{6}{|c|}{ Iron dose } \\
\hline 6-8 mg/day & & $0.54(0.44 ; 0.66)$ & 7,2089 & 18.4 & \multirow{3}{*}{0.32} \\
\hline$>8-10 \mathrm{mg} /$ day & & $0.59(0.45 ; 0.77)$ & 9,2575 & 85.2 & \\
\hline $11-15 \mathrm{mg} /$ day & & $0.82(0.51 ; 1.30)$ & 3,489 & 31.0 & \\
\hline Serum ferritin $(\mu \mathrm{g} / \mathrm{dL})$ & $17.3(13.5 ; 21.2)$ & & $21,(4291)$ & 95.1 & $<0.0001$ \\
\hline \multicolumn{6}{|c|}{ Iron dose } \\
\hline$<6 \mathrm{mg} /$ day & $5.8(-14.8 ; 26.3)$ & & 2,222 & 90.9 & \multirow{3}{*}{$<0.01$} \\
\hline 6-8 mg/day & $12.1(2.6 ; 21.7)$ & & 5,1261 & 96.4 & \\
\hline$>8-10 \mathrm{mg} /$ day & $27.5(16.0 ; 39.0)$ & & 9,2068 & 96.4 & \\
\hline \multicolumn{6}{|c|}{ Type of intervention } \\
\hline Supplementation & $27.2(18.2 ; 36.3)$ & & 8,1747 & 90.1 & \multirow{2}{*}{$<0.001$} \\
\hline Fortification & $11.3(13.7 ; 21.4)$ & & 13,2544 & 95.2 & \\
\hline \multicolumn{6}{|c|}{$\mathrm{RCT}$, quality rating } \\
\hline highest & $22.8(15.2 ; 30.4)$ & & 9,2351 & 93.0 & \multirow{3}{*}{0.08} \\
\hline intermediate & $11.4(6.6 ; 16.1)$ & & 9,1619 & 93.0 & \\
\hline lowest & $15.0(7.0 ; 23.0)$ & & 3,321 & 92.0 & \\
\hline \multicolumn{6}{|c|}{ Baseline ID prevalence } \\
\hline Low $(<15 \%)$ & $27.0(13.6 ; 40.4)$ & & 4,276 & 60.5 & \multirow{2}{*}{0.76} \\
\hline High $(\geq 15 \%)$ & $32.4(8.9 ; 55.9)$ & & 4,1226 & 98.3 & \\
\hline \multicolumn{6}{|c|}{ Baseline mean serum ferritin ${ }^{4}$} \\
\hline Low $(<29.2 \mu \mathrm{g} / \mathrm{L})$ & $18.5(11.7 ; 25.3)$ & & 9,1352 & 76.4 & \multirow{2}{*}{0.99} \\
\hline $\operatorname{High}(\geq 29.2 \mu \mathrm{g} / \mathrm{L})$ & $21.2(11.5 ; 30.9)$ & & 8,1698 & 94.0 & \\
\hline ID overall & & $0.22(0.14 ; 0.35)$ & 13,3698 & 86.3 & $<0.0001$ \\
\hline IDA overall & & $0.20(0.11 ; 0.37)$ & 8,3464 & 64.2 & $<0.0001$ \\
\hline
\end{tabular}

${ }^{1} \mathrm{Hb}$, hemoglobin, ID, iron deficiency; IDA, iron deficiency anemia; RCT, randomized controlled trial; ${ }^{2} 95 \%$ CI in parenthesis; ${ }^{3}$ Includes micronutrient powders and crushable tablets (foodlets); ${ }^{4}$ Low is defined as below 50 th percentile of all reported serum ferritin means; high is equal or above 50th percentile.

Effect on hemoglobin concentration: We identified 30 RCTs [26-55], contributing 43 comparisons, for evaluating the effect of up to $15 \mathrm{mg}$ of additional iron daily on hemoglobin levels of children 6-23 months of age. In total, 6569 children contributed to the pooled estimate. The iron interventions 
led to significantly higher hemoglobin concentrations in children, compared with no iron (pooled mean difference $4.07 \mathrm{~g} / \mathrm{L}$ (95\% CI: 2.82, 5.33; Figure S4), although there was significant heterogeneity of results $\left(I^{2} 82.5 \% ; p<0.0001\right)$. To examine the heterogeneity, we conducted meta-regression analyses and sub-group analyses investigating whether effect sizes were different for pre-specified sub-groups defined by the intervention dose (Figure S5), type of intervention (fortification vs. supplementation; Figure S6) and study quality (Figure S7). The increases in hemoglobin concentrations resulting from the intervention were significantly higher for supplementation trials than fortification trials $(p<0.01)$ and significantly lower as study quality worsened $(p<0.05)$. There was no significant difference in effect sizes by intervention dose $(p=0.12)$. Adjusting for these variables simultaneously did not substantially explain the observed heterogeneity (residual $I^{2} 81 \%, p<0.0001$ ).

Effect on anemia prevalence: 22 RCTs involving a total of 5647 children contributed $[26,27,29-32,34-$ $39,43-45,47,48,51,52,54-56]$ to the meta-analysis. The iron interventions resulted in a $41 \%$ reduction in children's risk of anemia compared with no iron (pooled relative risk (RR) 0.59 (95\% CI: 0.49 , 0.70 ), Figure S8), although there was considerable heterogeneity of results, $I^{2}: 73.8 \%$ ( $p$ value 0.0008 ). We investigated the influence of the intervention dose on effect sizes (Figure S9) and while it appears that interventions delivering 6-8 $\mathrm{mg}$ and $>8-10 \mathrm{mg}$ iron per day reduce the risk of anemia by $46 \%$ and $41 \%$, respectively, intervention dose did not significantly explain the differences in study effect sizes $(p=0.32)$. This agrees with the results of sub-group analyses for hemoglobin outcomes, where the largest effect sizes were observed for iron interventions delivering between $6 \mathrm{mg}$ and $10 \mathrm{mg}$ per day (Figure S5).

Effect on serum ferritin: Twenty-one RCTs [26-28,31-34,36-38,40,42,44,45,48-54], contributing 25 comparisons, provided sufficient data for the meta-analysis of the effect of low dose iron interventions on serum ferritin concentrations in young children. In total, 4291 children contributed to the pooled estimate. After pooling the results, the iron intervention resulted in significantly higher serum ferritin concentrations compared with controls (mean difference $17.3 \mu \mathrm{g} / \mathrm{L}$ (95\% CI: 13.1, 21.2; Figure S10), although there was significant heterogeneity, $I^{2} 95.1 \%(p<0.001)$. To understand the substantial heterogeneity in the results, we conducted meta-regression analyses and sub-group analyses investigating the influence of the dose (Figure S11), type of intervention (fortification vs. supplementation; Figure S12) and quality of interventions (Figure S13) on the effect size estimates. The effect sizes resulting from the intervention were significantly higher for higher doses $(p<0.01)$ and for supplementation trials compared with fortification trials $(p<0.001)$. Meta-regression results suggested that effects diminished as study quality worsened, although not significantly $(p=0.08)$. However, adjusting for dose, study quality, and intervention type simultaneously did not explain much of the observed heterogeneity (residual $I^{2} 88 \%$ ) and the change in effect size associated with increasing doses was no longer significant after adjusting for the quality of studies and type of intervention. We further examined the effect of baseline iron deficiency (categorized as low prevalence if $<15 \%$ and high prevalence if $\geq 15 \%$ ) on serum ferritin results. Only nine comparisons had information on baseline iron status. The pooled mean difference in serum ferritin for comparisons where baseline iron deficiency was high was not considerably different from the comparisons where baseline iron deficiency was low (Figure S14), and baseline iron deficiency did not explain the heterogeneity in serum ferritin results $(p$ value $=0.76$ ). Yet, with the limited number of studies, inadequate power could be a problem. In order to maximize the number of studies in the sub-group analysis, we created an 'in-house' measure of baseline iron status: from all reported mean serum ferritin concentrations, we took the 50th percentile $(29.2 \mathrm{ug} / \mathrm{L})$. Studies were categorized as having low iron status if mean serum ferritin was $<29.2$ and adequate if mean serum ferritin $\geq 29$.2. This variable could be created for 21 comparisons. However, even so, we did not detect a significant effect of baseline iron status and it did not account for the observed heterogeneity of serum ferritin results (Figure S15; $p$ value $=0.99$ ). The created variable may be an inadequate surrogate for participants' baseline iron deficiency levels. Effect on prevalence of ID and IDA: Thirteen trials $[26,29,31,32,34,36,38,39,43,45,48,52,54]$ and eight trials $[26,29,34-36,40,43,48]$ conducted mainly in Asia, provided 17 and 13 comparisons, respectively, 
that could be included in meta-analyses investigating the effect of the iron interventions on the risk of ID and IDA respectively among children 6-23 months old. The majority of trials defined ID as serum ferritin concentrations $<12 \mu \mathrm{g} / \mathrm{L}$ or $<10 \mu \mathrm{g} / \mathrm{L}$ while IDA was mainly defined as hemoglobin $<110 \mathrm{~g} / \mathrm{L}$ with serum ferritin concentrations $<12 \mu \mathrm{g} / \mathrm{L}$. The pooled relative risk from the random effects meta-analysis was 0.22 (95\% CI: 0.14, 0.35), $I^{2}: 86.3 \%$ (Figure S16) for ID and 0.20 (95\% CI: 0.11, 0.37), $I^{2}: 64.2 \%$ (Figure S17) for IDA, meaning that providing children 6-23 months old with up to $15 \mathrm{mg}$ of iron daily significantly reduced their risk of ID and IDA by $78 \%$ (95\% CI: $65 \%$ to $86 \%$ reduction) and $80 \%$ (95\% CI: $63 \%$ to $89 \%$ reduction) respectively.

Effect on growth: Ten RCTs examined the effect of iron on WAZ [35-38,41,43,44,48,52]; nine studies each contributed to the meta-analyses of the iron effect on WHZ [35-38,42-44,48,52] and HAZ [35-38,41,43,44,48,52]. There was no significant effect of iron on WAZ (Figure S18; Table 3; $p=0.69$ ), WHZ (Figure S19; Table 3; $p=0.62$ ) or HAZ (Figure S20; Table 3; $p=0.59$ ). Similarly, random effects meta-analysis indicated (Figures S21 and S22; Table 3) that there was no effect of iron on the risk for stunting [35-37,48] or wasting [35-37,48].

Effect on diarrhea, fever and respiratory infection: We identified eight eligible studies $[27,38,42,44,48$, $49,57,58]$, with a total of 11 comparisons, reporting on the impact of iron use on diarrhea, respiratory infection and/or fever. Given the variability of methods and outcome measures in the studies reviewed, it was not possible to conduct a meta-analysis without introducing a selection bias. The effect of iron alone was compared to placebo in seven RCTs, three compared the effect of iron and zinc to zinc alone, and one study compared the effect of MNP with and without iron on morbidity. Seven studies looked at the impact of iron on diarrhea, seven on respiratory infection and five on fever. None of the studies reported a beneficial effect of iron on any of the morbidities.

Effect on mental and motor development: Four eligible studies (five comparisons) reported children's Bayley mental development index (MDI; [27,36,51,54]) and Bayley psychomotor development index (PDI; [27,36,51,54]) scores. Children included in the analysis received daily 5-10 mg fortification or supplementation iron for 3-9 months. The analyses indicated that interventions delivering dietary doses of iron have no effect on mental development ( $p=0.6$; Figure S23; Table 3) and psychomotor development scores ( $p=0.5$; Figure S24; Table 3).

Table 3. Effects of daily iron administration ( $\leq 15 \mathrm{mg} /$ day) to children $6-23$ months on growth and mental and development outcomes ${ }^{1}$.

\begin{tabular}{cccccc}
\hline Variables & Mean Difference ${ }^{2}$ & Relative Risk & $\begin{array}{c}\text { Studies, } \\
\text { Participants }(\boldsymbol{n})\end{array}$ & $\mathbf{I}^{\mathbf{2}} \mathbf{( \% )} \begin{array}{c}p \text { Difference between } \\
\text { Pooled Intervention } \\
\text { and Control Groups }\end{array}$ \\
\hline \multicolumn{7}{c}{ Growth } \\
\hline WAZ & $-0.01(-0.08 ; 0.05)$ & 10,3511 & 12.5 & 0.69 \\
WHZ & $0.02(-0.06 ; 0.09)$ & 9,3297 & 36.8 & 0.62 \\
HAZ & $-0.02(-0.08 ; 0.04)$ & $1.09(0.92 ; 1.29)$ & 10,3511 & 8.2 & 0.57 \\
Stunting & & $1.11(0.84 ; 1.47)$ & 4,1975 & 0 & 0.33 \\
Wasting & & Mental and motor development & 0.45 \\
\hline \multicolumn{5}{c}{4,1062} \\
MDI & $0.4(-0.9 ; 1.7)$ & 4,1062 & 19.9 \\
PDI & $0.6(-1.2 ; 2.4)$ & 61.9 & 0.60 \\
\hline
\end{tabular}

${ }^{1}$ HAZ, height for age $z$-score; MDI, Bayley mental development index; PDI, Bayley psychomotor development index; WAZ, weight for age $z$-score; WHZ, weight for height $z$-score; ${ }^{2} 95 \% \mathrm{CI}$ in parenthesis.

\subsection{Zinc Interventions during Pregnancy and Lactation}

Few data on the effect of maternal supplementation on infant outcomes are available during pregnancy and the lactation period for most of the outcomes of interest and thus a meta-analysis was only conducted for birth outcomes. Results of single studies investigating growth and micronutrient status are discussed in the section below. 


\subsubsection{Effect on Birth Weight and Prevalence of Low Birth Weight}

The results of meta- analyses of studies conducted in pregnant women are summarized in Table 4.

Eight studies [59-66] and nine comparisons contributed to the meta-analysis for the effect of prenatal zinc use on birth weight, and six studies (seven comparisons) contributed to the meta-analysis of prenatal zinc and low birth weight prevalence $[59,61-63,65,67]$. We found that delivering up to $21 \mathrm{mg}$ of zinc daily during pregnancy has no significant effect on birth weights of offspring $(p=0.94$; Figure S25) or the prevalence of low birth weight ( $p=0.83$; Figure S26).

Table 4. Effects of administering $\leq 21 \mathrm{mg}$ /day zinc to pregnant women on birth weights and prevalence of low birth weight among their offspring.

\begin{tabular}{|c|c|c|c|c|c|}
\hline Variables & $\begin{array}{c}\text { Mean } \\
\text { Difference }{ }^{1}\end{array}$ & Relative Risk & $\begin{array}{c}\text { Studies, } \\
\text { Participants }(n)\end{array}$ & $I^{2}(\%)$ & $\begin{array}{l}p \text { Difference between } \\
\text { Pooled Intervention } \\
\text { and Control Groups }\end{array}$ \\
\hline \multicolumn{6}{|c|}{ Birth outcomes } \\
\hline Birthweight (g) & $1(-32 ; 35)$ & & 8,3457 & 0 & 0.94 \\
\hline Low birth weight & & $0.96(0.67 ; 1.37)$ & 6,2518 & 0 & 0.83 \\
\hline
\end{tabular}

\subsubsection{Effect on Infant Growth and Micronutrient Status}

Two studies examining child growth outcomes and one study examining the zinc status of children were identified. Prawirohartono et al. [60] looked at growth of infants whose mothers received either $20 \mathrm{mg}$ zinc only, vitamin A only, $20 \mathrm{mg}$ zinc and vitamin A or placebo during pregnancy. They monitored growth until 23 months of age. Zinc had a significant beneficial effect on HAZ at 6 months. No effects on any other growth parameters at any time point were observed. Iannotti et al. [68] administered $15 \mathrm{mg}$ zinc daily to pregnant women from gestational week 16 until 1 month after delivery and measured infant growth from birth to 12 months of age. They did not assess any predefined outcomes, but observed differences between intervention and control group in weight, calf, chest, mid-upper arm circumferences, and skinfold thicknesses from age 6 month to 12 month; and no effect on length or head circumference.

Caulfield and colleagues [59] looked at the zinc status of neonates after zinc supplementation of pregnant women. Women were included at gestational ages of 10-24 weeks and received a daily dose of $15 \mathrm{mg}$ zinc. They reported a significantly higher cord blood zinc concentration in neonates whose mothers received zinc supplementation, compared with controls.

Only one study was identified that investigated the effects of maternal zinc supplementation/ fortification during the lactation period on infant outcomes. The effect of maternal zinc supplementation on serum zinc concentration and growth in children after birth to 9 months of age was investigated by Salmenpera et al. [69]. They gave two different zinc doses ( $20 \mathrm{mg}, 40 \mathrm{mg}$ daily) to lactating women and compared the impact to a control group. Breast milk zinc concentration did not differ between groups at 0,2 , and 4 months after delivery, but was higher at 6 and 7.5 months in the group receiving $40 \mathrm{mg} /$ day of zinc. When analyses were restricted to exclusively breastfed infants, no difference in serum zinc concentration was detected between intervention and control groups at any time point and maternal zinc supplementation had no effect on infant growth.

\subsection{Zinc Interventions in Children 6-23 Months of Age}

\subsubsection{Effect on Serum or Plasma Zinc Concentrations and Zinc Deficiency}

The main results of the meta-analyses of studies in children investigating the effect of zinc administration on serum zinc and zinc status are presented in Table 5. 
Table 5. Effects of daily zinc administration $(\leq 10 \mathrm{mg})$ to children $6-23$ month on serum zinc and prevalence of zinc deficiency in children ${ }^{1}$.

\begin{tabular}{|c|c|c|c|c|c|}
\hline Variables & Mean Difference ${ }^{2}$ & Relative Risk & $\begin{array}{c}\text { Studies, } \\
\text { Participants }(n)\end{array}$ & $I^{2}(\%)$ & $\begin{array}{l}p \text { Difference between Pooled } \\
\text { Intervention and Control } \\
\text { Groups (Bold Font) and } \\
\text { Subgroups (Regular Font) }\end{array}$ \\
\hline $\begin{array}{c}\text { Serum zinc } \\
\text { overall }(\mu \mathrm{mol} / \mathrm{L})\end{array}$ & $2.0(1.2 ; 2.9)$ & & 23,8848 & 96.1 & $<0.0001$ \\
\hline \multicolumn{6}{|c|}{ Zinc dose } \\
\hline$<4 \mathrm{mg} /$ day & $0.81(-0.07 ; 1.68)$ & & 1,256 & 55.5 & \multirow{3}{*}{0.05} \\
\hline $4-<7 \mathrm{mg} /$ day & $0.9(0.08 ; 1.71)$ & & 7,1296 & 92.4 & \\
\hline $7-10 \mathrm{mg} /$ day & $3.0(1.5 ; 4.5)$ & & 14,6867 & 98.5 & \\
\hline \multicolumn{6}{|c|}{ Type of intervention } \\
\hline Supplementation & $2.4(1.5 ; 3.4)$ & & 19,7732 & 98.5 & \multirow{2}{*}{$<0.05$} \\
\hline Fortification ${ }^{3}$ & $0.3(-0.1 ; 0.8)$ & & 6,816 & 98.1 & \\
\hline \multicolumn{6}{|c|}{ Baseline ZD prevalence } \\
\hline Low $(<25 \%)$ & $2.9(0.2 ; 5.7)$ & & 4,1231 & 97.8 & \multirow{2}{*}{0.15} \\
\hline High $(\geq 25 \%)$ & $2.8(1.7 ; 3.9)$ & & 4,2372 & 95.5 & \\
\hline \multicolumn{6}{|c|}{ Baseline mean serum zinc ${ }^{4}$} \\
\hline \multirow{2}{*}{$\begin{array}{c}\text { Low }(<10.75 \mu \mathrm{g} / \mathrm{L}) \\
\text { High }(\geq 10.75 \\
\mu \mathrm{g} / \mathrm{L})\end{array}$} & $2.4(0.7 ; 4.2)$ & & 7,5635 & 98.7 & \multirow{2}{*}{0.96} \\
\hline & $2.3(0.7 ; 3.9)$ & & 9,2200 & 96.9 & \\
\hline ZD overall & & $0.47(0.32 ; 0.69)$ & 12,6666 & 92.2 & $<0.001$ \\
\hline
\end{tabular}

Twenty-three [36,43,48,59,70-88] RCTs (contributing 35 comparisons) provided sufficient information to be included in the meta-analysis summarizing the effect of up to $10 \mathrm{mg}$ of additional zinc daily on the serum or plasma zinc concentrations of children 6-23 months old.

The pooled estimate suggests that the zinc interventions significantly increased serum or plasma zinc concentrations by $2.03 \mu \mathrm{mol} / \mathrm{L}$ compared with no zinc (95\% CI 1.21, $2.85 \mu \mathrm{mol} / \mathrm{L} ; p<0.0001$, Figure S27), but with significant heterogeneity ( $\left.I^{2} 98 \%\right)$. Meta-regression analyses suggest that effect sizes were larger at higher doses $(p<0.05$, Figure S28), and for supplementation compared with fortification trials ( $p=0.05$, Figure S29), while study quality did not significantly explain the heterogeneity. Dose, intervention type and study quality together did little to explain the heterogeneity of findings (residual $I^{2} 97.9 \%$ ). Subgroup analyses stratified by dose suggested that the strongest effect on serum zinc was obtained in studies delivering daily $7-10 \mathrm{mg}(3.0 \mu \mathrm{mol} / \mathrm{L} ;(95 \% \mathrm{CI} 1.51,4.48))$. A small but significant effect was also detected in studies administering $4-<7 \mathrm{mg} /$ day $(0.9 \mu \mathrm{mol} / \mathrm{L}$ (95\% CI 0.08, 1.71; Figure S28)). Stratification by intervention type revealed that the pooled effect size of fortification trials on serum zinc concentrations was small and not statistically significant $(0.31 \mu \mathrm{mol} / \mathrm{L}$ (95\% CI $-0.12,0.75$; Figure S29), whereas supplementation showed a larger and significant difference $(2.07 \mu \mathrm{mol} / \mathrm{L}(95 \%$ CI $1.5,3.4)$.

Baseline zinc deficiency levels were reported for 12 comparisons with serum zinc as the outcome. We categorized baseline zinc deficiency as low prevalence if $<25 \%$ and high prevalence if $\geq 25 \%$. The pooled mean difference in serum zinc was similar regardless of baseline zinc deficiency status (Figure S30), and baseline zinc deficiency explains $8.4 \%$ of the heterogeneity in serum zinc results ( $p$ value $=0.15$ ). In order to maximize the number of studies in the sub-group analysis, we created a measure of baseline zinc status: from all reported serum zinc means, we took the 50th percentile $(10.75 \mu \mathrm{mol} / \mathrm{L})$. Studies were categorized as having low zinc status if mean serum zinc was $<10.75 \mu \mathrm{mol} / \mathrm{L}$ and adequate if mean serum zinc $\geq 10.75$. This variable could be created for 25 comparisons. It did not explain any of the observed heterogeneity of serum zinc results ( $p$ value $=0.96$; Figure S32). The created variable may be an inadequate surrogate for participants' baseline zinc deficiency levels. 
For the effect of zinc interventions on the risk of zinc deficiency among children 6-23 months old, 12 RCTs $[35,39,43,48,71,72,74,77,78,81,84,87]$, which provided 22 comparisons, contributed to the meta-analysis. Half defined zinc deficiency as serum or plasma zinc concentrations $<10.7 \mu \mathrm{mol} / \mathrm{L}$, while the others defined it using a cutoff of $<\sim 9.9 \mu \mathrm{mol} / \mathrm{L}$.

The pooled relative risk from the random effects meta-analysis was 0.47 (95\% CI 0.32, 0.69), $I^{2}: 92 \%$, meaning that providing children 6-23 months old with up to $10 \mathrm{mg}$ of zinc daily significantly reduced their risk of zinc deficiency by 53\% (95\% CI 25\% to 64\% reduction; Figure S32).

\subsubsection{Effect on Growth}

Results of studies investigating effects of zinc interventions on child growth are summarized in Table 6.

Table 6. Effects of daily zinc administration $(\leq 10 \mathrm{mg})$ to children $6-23$ month on growth ${ }^{1}$.

\begin{tabular}{cccccc}
\hline Variables & $\begin{array}{c}\text { Mean } \\
\text { Difference }\end{array}$ & Relative Risk & $\begin{array}{c}\text { Studies, } \\
\text { Participants }(\boldsymbol{n})\end{array}$ & $\mathbf{I}^{\mathbf{2}} \mathbf{( \% )} \begin{array}{c}p \text { Difference between } \\
\text { Pooled Intervention } \\
\text { and Control Groups }\end{array}$ \\
\hline WAZ & $0.05(0.00 ; 0.10)$ & \multicolumn{2}{c}{ Growth } \\
WHZ & $0.04(0.00 ; 0.08)$ & & 21,7440 & 39.4 & 0.04 \\
HAZ & $0.00(-0.04 ; 0.03)$ & 16,6875 & 22.3 & 0.04 \\
Stunting & & $0.97(0.90 ; 1.04)$ & 20,7340 & 9.2 & 0.80 \\
Wasting & & $0.98(0.79 ; 1.21)$ & 6,5443 & 0 & 0.39 \\
Underweight & & $0.99(0.90 ; 1.09)$ & 5,4793 & 32.0 & 0.82 \\
\hline
\end{tabular}

${ }^{1} \mathrm{HAZ}$, height for age $z$-score; WAZ, weight for age $z$-score; WHZ, weight for height $z$-score; ${ }^{2} 95 \% \mathrm{CI}$ in parenthesis.

Twenty-one [36,37,43,48,74,75,78,83-86,88-97] studies (31 comparisons) contributed to meta-analyses of zinc effects on WAZ, and 20 studies yielding 30 comparisons [36,37,43,48,74,75, 78,82-86,88-92,94,95,97] reported HAZ outcomes. The WHZ meta-analysis included 16 studies [36,37, $43,48,74,75,78,82,84,85,88-92,97]$ with 25 comparisons. After pooling the studies, zinc interventions compared with placebo or no zinc slightly but significantly increased WAZ (mean difference: 0.05, 95\% CI 0.0, 0.1) and WHZ (mean difference: $0.04,95 \%$ CI 0.0, 0.08), while the HAZ result was not significant (mean difference: 0.00, 95\% CI -0.04, 0.03; Figures S33-S35).

Fewer studies categorized children as stunted, wasted or underweight. Six studies with 10 comparisons [36,37,48,74,76,79] were included in the meta-analysis for the effect of zinc interventions on childhood stunting (HAZ <-2), five studies with eight comparisons $[37,74,76,79]$ in the meta-analysis for childhood underweight, and six studies yielding 10 comparisons [36,37,48,74,76,79] in the meta-analysis for childhood wasting.

The zinc interventions were not associated with significant reductions in the risk of child stunting (RR 0.97, 95\% CI 0.9, 1.04), wasting (RR 0.98, 95\% CI 0.79, 1.21) or underweight (RR 0.99, 95\% CI 0.90, 1.09; Figures S36-S38).

\subsubsection{Effects on Diarrhea, Fever, and Respiratory Infections}

In total, we identified 24 studies [48,57,70,71,73-77,79,82,85,87-91,93,97-103], with 33 comparisons, meeting our inclusion criteria and reporting on the impact of zinc on diarrhea, respiratory infections and fever. Twenty-one studies were individually randomized and three studies cluster randomized trials. We decided not to do a meta-analysis given the considerable variability of methods and outcome measures in the studies reviewed: more than half of the studies could not have been included in the analysis and thus, results might have been biased.

Similar to previous reviews, we found conflicting results for the effect of zinc intake on diarrhea, but not on respiratory infection and fever prevalence and/or incidence. Of the 
16 studies $[48,57,70,75,82,85,87,88,91,97,99,100,102-105]$ reporting on fever and/or respiratory infections, only $3[82,91,104]$ found a positive effect of zinc intake. Out of the 24 studies investigating the effect of zinc on diarrhea, 11 studies [48,57,70,74-76,79,85,87,88,99] found no effect at all. Ten $[71,73,89-91,93,97,100-102]$ reported a positive effect of zinc use on the prevalence and or incidence of diarrhea. Two $[82,103]$ found a significant positive effect of zinc on diarrhea in the stunted sub-group, and Sazawal et al. [77] reported only a significant effect of zinc in children with low serum zinc concentrations and children older than 11 month of age. Age dependency has also been reported by Wuehler et al. [97], with a strong effect in the age group of 11.5-17.4 months and no effect in older children (17.5-30 months).

\subsubsection{Effects on Mental and Motor Development}

Three $[57,106,107]$ eligible studies reported MDI and PDI scores and found no significant impact of zinc interventions on the two outcomes.

\subsection{The Interaction of Iron and Zinc in Interventions in Children 6-23 Months of Age}

\subsubsection{Effect of Zinc on Serum Ferritin}

Sub-group analyses of the 21 RCTs [26-28,31-34,36-38,40,42,44,45,48-54] reporting on the effect of iron interventions on serum ferritin indicated that iron has the strongest beneficial effect when it is the sole micronutrient administered (mean increase of $26.1 \mu \mathrm{g} / \mathrm{L}$ ) and that it has a smaller, albeit significant, effect on serum ferritin when it is administered in combination with zinc (Figure 1).

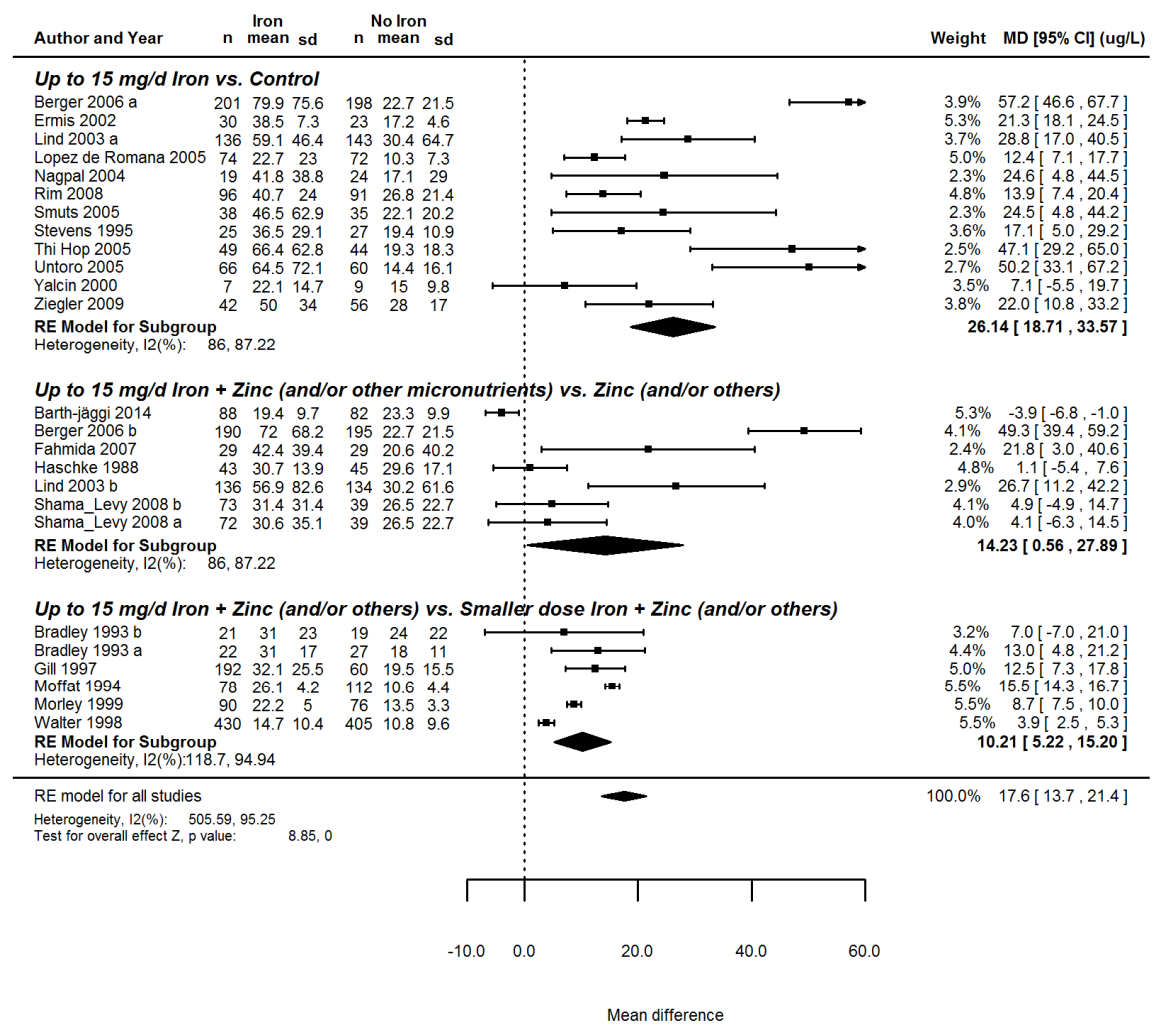

Figure 1. Forest plot summarizing the interactions of iron and zinc, supplying up to $15 \mathrm{mg}$ of additional iron daily to children 6-23 months old on serum ferritin.

\subsubsection{The Effect of Iron on Serum Zinc}

We found 23 studies [36,43,48,59,70-88], with 35 comparisons, 14 of them comparing zinc alone to placebo, 17 of them comparing zinc in combination with iron to iron only and four of them comparing 
zinc and other micronutrients to other micronutrients. Sub-group analyses showed that if iron was part of the intervention, the effect of zinc on serum/plasma zinc concentrations was considerably lower $(1.02 \mu \mathrm{mol} / \mathrm{L}, 95 \% \mathrm{CI} 0.28,1.76)$, compared to interventions delivering zinc alone $(3.04 \mu \mathrm{mol} / \mathrm{L}, 95 \% \mathrm{CI}$ $1.16,4.92)$ and to interventions delivering zinc and other micronutrients, excluding iron $(2.77 \mu \mathrm{mol} / \mathrm{L}$, 95\% CI 0.13, 5.42; Figure 2).

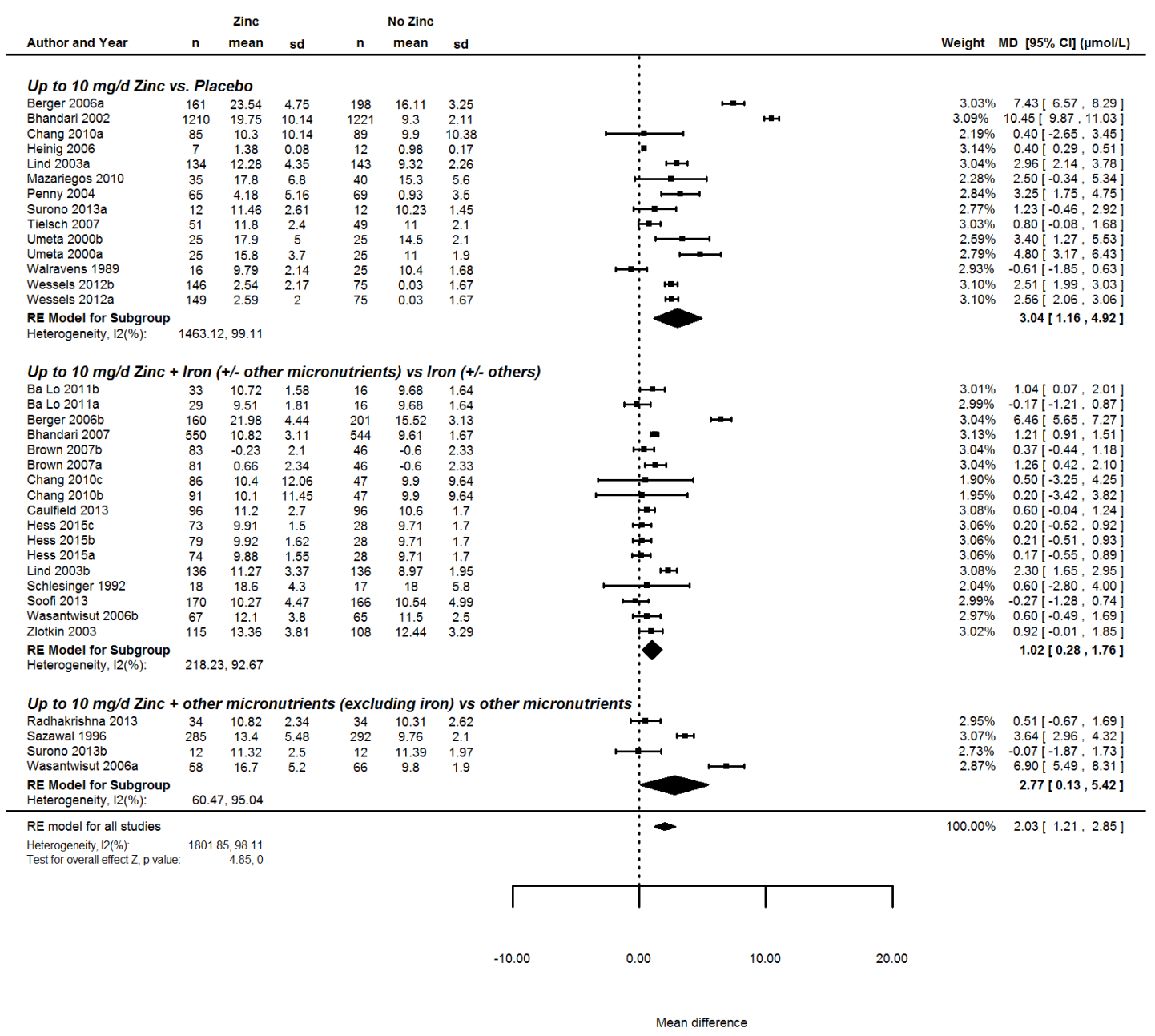

Figure 2. Forest plot summarizing the effect of interventions supplying up to $10 \mathrm{mg}$ of additional zinc daily to children 6-23 months old, on serum or plasma zinc concentrations, stratified by micronutrient composition.

\subsection{Quality of the Evidence across Studies}

We used the GRADE approach to assess the quality of evidence across studies (Table S1). We considered that a publication bias or imprecision was unlikely for all outcomes. In contrast, the large heterogeneity, the lack of studies, and indirectness were considered important factors in the quality of evidence across studies. For indirectness of evidence we rated down in case $\geq 50 \%$ of the included studies was not food based interventions. For interventions delivering iron compared to a placebo group, the overall quality of evidence was found to be high for iron status (using serum ferritin concentration), ID and IDA; moderate for hemoglobin, HAZ, WAZ, and WHZ; low for anemia, stunting and wasting, whereas for birth weight, low birth weight, MDI and PDI the quality of evidence was very low. For interventions administering zinc compared to placebo the quality of evidence was moderate for birth weight, prevalence of low birth weight, zinc deficiency, zinc status (using serum zinc concentration), stunting, wasting, HAZ, WAZ, and WHZ, and low for underweight. 


\section{Discussion}

We found that interventions delivering iron and zinc in concentrations up to the RNI during the 1000 days window from the prenatal period to the first 2 years of a child's life can have positive impacts on the iron and zinc status of young children. In particular, when interventions were conducted in children aged 6-23 months old, their hemoglobin levels, and iron and zinc status improved. For both nutrients, supplementation triggered a significantly stronger response than fortification even when doses were similar. For other outcomes assessed-birth weight, growth in childhood, psychomotor development-findings are less conclusive, partly due to the limited number of studies.

We show that low dose iron and zinc interventions providing no more than $45 \mathrm{mg} /$ day of iron and $20 \mathrm{mg}$ /day of zinc during pregnancy may not have an impact on children's birth weights and prevalence of low birth weight. Similar to our results, other meta-analyses found no effect of zinc on birth weight and prevalence of low birth weight $[108,109]$. Most of the studies included in those analyses did not meet our inclusion criteria because they gave higher doses of zinc than we were interested in. For iron, our results are also in accordance with a recent meta-analysis, which only observed beneficial effects at iron doses exceeding our threshold [110]. However, due to the scarcity of studies having follow-up data extending beyond the perinatal period, it is unclear if any growth advantages of routine iron and zinc ingestion during pregnancy could manifest later in infancy or early childhood.

We found that the use of iron in dietary doses (no more than $15 \mathrm{mg} /$ day) during infancy and early childhood had positive effects on hemoglobin levels, anemia prevalence, and iron status (serum ferritin, ID and IDA prevalence), which agrees with a systematic review published in 2012 assessing the effect of micronutrient-fortified milk and cereal foods on infants and children [111] and a meta-analysis of supplementation trials in children 6-23 month of age, published in 2013 [112]. We did not find an effect of iron interventions on child growth or morbidity, suggesting that food-based iron interventions at doses investigated here have no beneficial impact on the occurrence of childhood morbidities. Limited effects of iron can be expected regarding mental and motor development until the age of 2 years (we focused on the Bayley's scales for mental and motor development due to more consistent reporting).

We conducted sub-group analyses stratified by type of intervention (fortification/ supplementation), intervention dose, a measure of baseline micronutrient status, as well as study quality. Sub-group analyses demonstrated that iron administered as fortificants significantly increased serum ferritin and hemoglobin levels, although to a lesser extent than supplements. This could be due to the presence of absorption inhibitors in fortified foods. For biofortification, the magnitude of the effect on iron and zinc status is unclear as to date no biofortification trials have been conducted with a focus on the 1000 days window. Yet, we would expect comparable effects as observed from fortification since both approaches deliver the micronutrients together with other dietary components. Sub-group analysis stratified by dose showed that daily iron doses as low as 6-8 $\mathrm{mg}$ increased serum ferritin levels. Larger effect sizes were observed for higher daily iron doses (8-10 mg), however, such doses might be difficult to attain for infants by dietary diversification or biofortification interventions alone. Surprisingly, baseline iron status did not explain much of the heterogeneity of the findings in our analysis. This is somewhat in contrast to previously published data $[113,114]$ and could be ascribed to other factors influencing iron absorption and utilization in contexts of high exposure to inflammation [115]. But also, the categorization of studies into iron deficient versus iron sufficient population had to be done in a relatively crude manner.

We found that zinc supplementation at doses no higher than $10 \mathrm{mg} /$ day increased the serum zinc concentrations of children and reduced the risk of suffering from zinc deficiency, whereas the effect of zinc administered in fortification trials, although in comparable concentrations as supplemental zinc, had no significant effect on serum zinc levels. We did not find any modification of the zinc intervention effects by child baseline zinc status. Sub-group analysis stratified by dose showed that daily zinc doses of 4-6 mg increased serum zinc by $0.9 \mu \mathrm{mol} / \mathrm{L}$ while larger effect sizes were observed for higher zinc doses 7-10 mg, which might be difficult to reach in children 6-23 months old through dietary means 
alone. Effects of zinc were significant for WHZ and WAZ, although the differences remained rather small, compared with controls. Zinc interventions probably do not have a measurable effect on the occurrence of respiratory infections and fever and effects on diarrhea are inconclusive.

Lastly, we found that, when zinc and iron were given together, their beneficial effects on serum zinc and serum iron levels were weaker than when each nutrient was given alone, suggesting that iron and zinc compete for absorption from the gut, a finding that has previously been posited [116].

Possible limitations of the review should be noted. First, many results exhibit large amounts of heterogeneity, which could not be explained by the factors we explored, and which are probably due to the differences in study design, the different types of interventions and reporting. Thus, the pooled estimates of some of the effects shown may be imprecise and results have to be interpreted with caution. Second, none of the studies meeting our inclusion criteria covered the full 1000 days window meaning that the impacts of the micronutrients could not be assessed holistically across the different life stages, but only in a compartmentalized manner. Thus, no statements can be made about whether a holistic approach covering the full 1000 days (iron and zinc interventions starting during pregnancy and continuing until 2 years of age) would have a synergistic or additive effect on certain outcome measures.

To illustrate this using ferritin levels and the Psychomotor Development Index, the absorption and utilization of dietary iron is affected by the subject's iron status $[117,118]$. Thus, if an iron intervention given to pregnant women suffering from moderate to severe dietary iron deficiency anemia has a positive effect on the fetus's iron status, infants born to such women would have a better iron status than control peers of the same age whose mothers received no iron [119]. Continuing the higher iron regime into infancy could actually decrease iron absorption/utilization by children in the intervention group, assuming they had benefited from exposure to prenatal use, while children in the prenatal control group who start receiving iron after birth may more efficiently absorb and utilize the little iron available. Taken together, it is possible that only small differences in iron status would be observed between the two groups at the age of two years. In contrast, with regard to the Psychomotor Development Index, one could imagine that a 1000-day intervention could lead to a synergistic effect, since some early neurodevelopmental constraints are partly irreversible [120]. Thus, a child exposed to prenatal iron would be primed for a better start early in life. Third, only few studies assessed the inflammatory status of the children and reported prevalence of inflammation and therefore it was not possible to stratify studies by level of inflammation. During inflammation the human body down regulates iron absorption, and thus studies with a high proportion of subjects suffering from inflammation would be expected to show less effects of iron on iron status. Also, in those populations, an effect of iron on hemoglobin and anemia prevalence could be masked by anemia of inflammation in the same subject.

To conclude, providing dietary or relatively low daily doses of iron and zinc to young children could be beneficial for their iron and zinc status, indicating that food based approaches can be useful tools to reduce the prevalence of iron and zinc deficiencies. However, it is questionable if an intervention would affect child outcomes throughout the whole 1000 days period, not least because of breast milk iron and zinc homeostasis [121-124]. More research assessing the impact of iron and zinc holistically over the different life stages (pregnancy, lactation, and early childhood) is required to understand the potential role of interventions provided throughout the 1000 days window.

Supplementary Materials: The following are available online at http:/ www.mdpi.com/2072-6643/8/12/773/s1.

Acknowledgments: Parts of data presented in this article were discussed during an expert consultation, organized by HarvestPlus on 31 March 2016, and we are thankful for all the comments from these participants.

Author Contributions: N.P., E.B., M.D.A. and F.R. designed the review. I.O. and N.P. conducted the analyses. N.P. wrote the first draft of the manuscript, and all authors contributed to the editing of the manuscript. All authors approved the final manuscript.

Conflicts of Interest: The review was funded by HarvestPlus. The authors declare no conflict of interest. 


\section{References}

1. World Health Organization (WHO). Guidelines for Food Fortification; World Health Organization: Geneva, Switzerland, 2006. Available online: http://www.who.int/nutrition/publications/guide_food_fortification_ micronutrients.pdf (accessed on 15 August 2016).

2. Murray, C.J.L.; Vos, T.; Lozano, R.; Naghavi, M.; Flaxman, A.D.; Michaud, C.; Ezzati, M.; Shibuya, K.; Salomon, J.A.; Abdalla, S.; et al. Disability-adjusted life years (DALYs) for 291 diseases and injuries in 21 regions, 1990-2010: A systematic analysis for the Global Burden of Disease Study 2010. Lancet 2012, 380, 2197-2223. [CrossRef]

3. Victora, C.G.; Adair, L.; Fall, C.; Hallal, P.C.; Martorell, R.; Richter, L.; Sachdev, H.S.; Study, M.C.U. Maternal and child undernutrition 2-Maternal and child undernutrition: Consequences for adult health and human capital. Lancet 2008, 371, 340-357. [CrossRef]

4. Black, M.M.; Quigg, A.M.; Hurley, K.M.; Pepper, M.R. Iron deficiency and iron-deficiency anemia in the first two years of life: Strategies to prevent loss of developmental potential. Nutr. Rev. 2011, 69, S64-S70. [CrossRef] [PubMed]

5. Black, M.M. Integrated strategies needed to prevent iron deficiency and to promote early child development. J. Trace Elem. Med. Biol. 2012, 26, 120-123. [CrossRef] [PubMed]

6. Oski, F.A. Iron-Deficiency in Infancy and Childhood. N. Engl. J. Med. 1993, 329, 190-193. [PubMed]

7. Christian, P.; Stewart, C.P. Maternal micronutrient deficiency, fetal development, and the risk of chronic disease. J. Nutr. 2010, 140, 437-445. [CrossRef] [PubMed]

8. Hess, S.Y.; Lonnerdal, B.; Hotz, C.; Rivera, J.A.; Brown, K.H. Recent advances in knowledge of zinc nutrition and human health. Food Nutr. Bull. 2009, 30, S5-S11. [CrossRef] [PubMed]

9. Bouis, H.E. Micronutrient fortification of plants through plant breeding: Can it improve nutrition in man at low cost? Proc. Nutr. Soc. 2003, 62, 403-411. [CrossRef] [PubMed]

10. Kau, A.L.; Ahern, P.P.; Griffin, N.W.; Goodman, A.L.; Gordon, J.I. Human nutrition, the gut microbiome and the immune system. Nature 2011, 474, 327-336. [CrossRef] [PubMed]

11. Muller, O.; Krawinkel, M. Malnutrition and health in developing countries. CMAJ 2005, 173, $279-286$. [CrossRef] [PubMed]

12. Sazawal, S.; Black, R.E.; Ramsan, M.; Chwaya, H.M.; Stoltzfus, R.J.; Dutta, A.; Dhingra, U.; Kabole, I.; Deb, S.; Othman, M.K.; et al. Effects of routine prophylactic supplementation with iron and folic acid on admission to hospital and mortality in preschool children in a high malaria transmission setting: Community-based, randomised, placebo-controlled trial. Lancet 2006, 367, 133-143. [CrossRef]

13. Hozo, S.P.; Djulbegovic, B.; Hozo, I. Estimating the mean and variance from the median, range, and the size of a sample. BMC Med. Res. Methodol. 2005, 5, 13. [CrossRef] [PubMed]

14. Higgins, J.P.; White, I.R.; Anzures-Cabrera, J. Meta-analysis of skewed data: Combining results reported on log-transformed or raw scales. Stat. Med. 2008, 27, 6072-6092. [CrossRef] [PubMed]

15. DerSimonian, R.; Laird, N. Meta-analysis in clinical trials. Contr. Clin. Trial. 1986, 7, 177-188. [CrossRef]

16. Higgins, J.P.T.; Green, S. Reviews of Interventions 4.2.6. In The Cochrane Library; John Wiley \& Sons, Ltd.: Chichester, UK, 2006; Volume 4.

17. Viechtbauer, W. Conducting Meta-Analyses in R with the metafor Package. J. Stat. Softw. 2010, 36, 1-48. [CrossRef]

18. Schünemann, H.; Brożek, J.; Guyatt, G.; Oxman, A. GRADE Handbook. Introduction to GRADE Handbook. GRADE Working Group, 2013. Available online: http://gdt.guidelinedevelopment.org/app/handbook/ handbook.html (accessed on 28 November 2016).

19. Liu, J.M.; Mei, Z.G.; Ye, R.W.; Serdula, M.K.; Ren, A.G.; Cogswell, M.E. Micronutrient Supplementation and Pregnancy Outcomes Double-Blind Randomized Controlled Trial in China. JAMA Intern. Med. 2013, 173, 276-282. [CrossRef] [PubMed]

20. Ouladsahebmadarek, E.; Sayyah-Melli, M.; Taghavi, S.; Abbasalizadeh, S.; Seyedhejazie, M. The effect of supplemental iron elimination on pregnancy outcome. Pak. J. Med. Sci. 2011, 27, 641-645.

21. Makrides, M.; Crowther, C.A.; Gibson, R.A.; Gibson, R.S.; Skeaff, C.M. Efficacy and tolerability of low-dose iron supplements during pregnancy: A randomized controlled trial. Am. J. Clin. Nutr. 2003, 78, 145-153. [PubMed] 
22. Siega-Riz, A.M.; Hartzema, A.G.; Turnbull, C.; Thorp, J.; McDonald, T.; Cogswell, M.E. The effects of prophylactic iron given in prenatal supplements on iron status and birth outcomes: A randomized controlled trial. Am. J. Obstet. Gynecol. 2006, 194, 512-519. [CrossRef] [PubMed]

23. Cogswell, M.E.; Parvanta, I.; Ickes, L.; Yip, R.; Brittenham, G.M. Iron supplementation during pregnancy, anemia, and birth weight: A randomized controlled trial. Am. J. Clin. Nutr. 2003, 78, 773-781. [PubMed]

24. Dawson, E.B.; Albers, J.; Mcganity, W.J. Serum Zinc Changes Due to Iron Supplementation in Teen-Age Pregnancy. Am. J. Clin. Nutr. 1989, 50, 848-852. [PubMed]

25. Li, Q.; Yan, H.; Zeng, L.X.; Cheng, Y.; Liang, W.F.; Dang, S.N.; Wang, Q.L.; Tsuji, I. Effects of Maternal Multimicronutrient Supplementation on the Mental Development of Infants in Rural Western China: Follow-up Evaluation of a Double-Blind, Randomized, Controlled Trial. Pediatrics 2009, 123, E685-E692. [CrossRef] [PubMed]

26. Walter, T.; Pino, P.; Pizarro, F.; Lozoff, B. Prevention of iron-deficiency anemia: Comparison of high- and low-iron formulas in term healthy infants after six months of life. J. Pediatr. 1998, 132, 635-640. [CrossRef]

27. Moffatt, M.E.; Longstaffe, S.; Besant, J.; Dureski, C. Prevention of iron deficiency and psychomotor decline in high-risk infants through use of iron-fortified infant formula: A randomized clinical trial. J. Pediatr. 1994, 125, 527-534. [CrossRef]

28. Ermis, B.; Demirel, F.; Demircan, N.; Gurel, A. Effects of three different iron supplementations in term healthy infants after 5 months of life. J. Trop. Pediatr. 2002, 48, 280-284. [CrossRef] [PubMed]

29. Geltman, P.L.; Meyers, A.F.; Mehta, S.D.; Brugnara, C.; Villon, I.; Wu, Y.A.; Bauchner, H. Daily multivitamins with iron to prevent anemia in high-risk infants: A randomized clinical trial. Pediatrics 2004, 114, 86-93. [CrossRef] [PubMed]

30. Walter, T.; Dallman, P.R.; Pizarro, F.; Velozo, L.; Pena, G.; Bartholmey, S.J.; Hertrampf, E.; Olivares, M.; Letelier, A.; Arredondo, M. Effectiveness of iron-fortified infant cereal in prevention of iron deficiency anemia. Pediatrics 1993, 91, 976-982. [PubMed]

31. Gill, D.G.; Vincent, S.; Segal, D.S. Follow-on formula in the prevention of iron deficiency: A multicentre study. Acta Paediatr. 1997, 86, 683-689. [CrossRef] [PubMed]

32. Haschke, F.; Pietschnig, B.; Vanura, H.; Heil, M.; Steffan, I.; Hobiger, G.; Schuster, E.; Camaya, Z. Iron intake and iron nutritional status of infants fed iron-fortified beikost with meat. Am. J. Clin. Nutr. 1988, 47, 108-112. [PubMed]

33. Ziegler, E.E.; Nelson, S.E.; Jeter, J.M. Iron status of breastfed infants is improved equally by medicinal iron and iron-fortified cereal. Am. J. Clin. Nutr. 2009, 90, 76-87. [CrossRef] [PubMed]

34. Rim, H.; Kim, S.; Sim, B.; Gang, H.; Kim, H.; Kim, Y.; Kim, R.; Yang, M. Effect of iron fortification of nursery complementary food on iron status of infants in the DPRKorea. Asia Pac. J. Clin. Nutr. 2008, 17, 264-269. [PubMed]

35. Dijkhuizen, M.A.; Wieringa, F.T.; West, C.E.; Martuti, S. Muhilal: Effects of iron and zinc supplementation in Indonesian infants on micronutrient status and growth. J. Nutr. 2001, 131, 2860-2865. [PubMed]

36. Lind, T.; Lonnerdal, B.; Stenlund, H.; Ismail, D.; Seswandhana, R.; Ekstrom, E.C.; Persson, L.A. A community-based randomized controlled trial of iron and zinc supplementation in Indonesian infants: Interactions between iron and zinc. Am. J. Clin. Nutr. 2003, 77, 883-890. [PubMed]

37. Fahmida, U.; Rumawas, J.S.; Utomo, B.; Patmonodewo, S.; Schultink, W. Zinc-iron, but not zinc-alone supplementation, increased linear growth of stunted infants with low haemoglobin. Asia Pac. J. Clin. Nutr. 2007, 16, 301-309. [PubMed]

38. Untoro, J.; Karyadi, E.; Wibowo, L.; Erhardt, M.W.; Gross, R. Multiple micronutrient supplements improve micronutrient status and anemia but not growth and morbidity of Indonesian infants: A randomized, double-blind, placebo-controlled trial. J. Nutr. 2005, 135, 639S-645S. [PubMed]

39. Wieringa, F.T.; Dijkhuizen, M.A.; West, C.E.; Thurnham, D.I.; Muhilal; Van der Meer, J.W.M. Redistribution of vitamin A after iron supplementation in Indonesian infants. Am. J. Clin. Nutr. 2003, 77, 651-657. [PubMed]

40. Shamah-Levy, T.; Villalpando, S.; Rivera-Dommarco, J.A.; Mundo-Rosas, V.; Cuevas-Nasu, L.; Jimenez-Aguilar, A. Ferrous gluconate and ferrous sulfate added to a complementary food distributed by the Mexican nutrition program Oportunidades have a comparable efficacy to reduce iron deficiency in toddlers. J. Pediatr. Gastroenterol. Nutr. 2008, 47, 660-666. [CrossRef] [PubMed] 
41. Domellof, M.; Cohen, R.J.; Dewey, K.G.; Hernell, O.; Rivera, L.L.; Lonnerdal, B. Iron supplementation of breast-fed Honduran and Swedish infants from 4 to 9 months of age. J. Pediatr. 2001, 138, 679-687. [CrossRef] [PubMed]

42. Smuts, C.M.; Dhansay, M.A.; Faber, M.; van Stuijvenberg, M.E.; Swanevelder, S.; Gross, R.; Benade, A.J.S. Efficacy of multiple micronutrient supplementation for improving anemia, micronutrient status, and growth in south African infants. J. Nutr. 2005, 135, 653S-659S. [PubMed]

43. Wasantwisut, E.; Winichagoon, P.; Chitchumroonchokchai, C.; Yamborisut, U.; Boonpraderm, A.; Pongcharoen, T.; Sranacharoenpong, K.; Russameesopaphorn, W. Iron and zinc supplementation improved iron and zinc status, but not physical growth, of apparently healthy, breast-fed infants in rural communities of northeast Thailand. J. Nutr. 2006, 136, 2405-2411. [PubMed]

44. De Romana, G.L.; Cusirramos, S.; de Romana, D.L.; Gross, R. Efficacy of multiple micronutrient supplementation for improving anemia, micronutrient status, growth, and morbidity of Peruvian infants. J. Nutr. 2005, 135, 646S-652S.

45. Stevens, D.; Nelson, A. The Effect of Iron in Formula Milk after 6 Months of Age. Arch. Dis. Child. 1995, 73, 216-220. [CrossRef] [PubMed]

46. Virtanen, M.A.; Svahn, C.J.; Viinikka, L.U.; Raiha, N.C.; Siimes, M.A.; Axelsson, I.E. Iron-fortified and unfortified cow's milk: Effects on iron intakes and iron status in young children. Acta Paediatr. 2001, 90, 724-731. [CrossRef] [PubMed]

47. Nogueira Arcanjo, F.P.; Santos, P.R.; Costa Arcanjo, C.P.; Meira Magalhaes, S.M.; Madeiro Leite, A.J. Daily and Weekly Iron Supplementations are Effective in Increasing Hemoglobin and Reducing Anemia in Infants. J. Trop. Pediatr. 2013, 59, 175-179. [CrossRef] [PubMed]

48. Berger, J.; Ninh, N.X.; Khan, N.C.; Nhien, N.V.; Lien, D.K.; Trung, N.Q.; Khoi, H.H. Efficacy of combined iron and zinc supplementation on micronutrient status and growth in Vietnamese infants. Eur. J. Clin. Nutr. 2006, 60, 443-454. [CrossRef] [PubMed]

49. Barth-Jaeggi, T.; Moretti, D.; Kvalsvig, J.D.; Holding, P.A.; Njenga, J.; Mwangi, A.; Chhagan, M.; Lacroix, C.; Zimmermann, M.B. In-home fortification with $2.5 \mathrm{mg}$ iron as NaFeEDTA does not reduce anaemia but increases weight gain: A randomised controlled trial in Kenyan infants. Matern. Child Nutr. 2015, 11, 151-162. [CrossRef] [PubMed]

50. Nagpal, J.; Sachdev, H.P.S.; Singh, T.; Mallika, V. A randomized placebo-controlled trial of iron supplementation in breastfed young infants initiated on complementary feeding: Effect on haematological status. J. Health Popul. Nutr. 2004, 22, 203-211. [PubMed]

51. Morley, R.; Abbott, R.; Fairweather-Tait, S.; MacFadyen, U.; Stephenson, T.; Lucas, A. Iron fortified follow on formula from 9 to 18 months improves iron status but not development or growth: A randomised trial. Arch. Dis. Child. 1999, 81, 247-252. [CrossRef] [PubMed]

52. Hop, L.T.; Berger, J. Multiple micronutrient supplementation improves anemia, micronutrient nutrient status, and growth of Vietnamese infants: Double-blind, randomized, placebo-controlled trial. J. Nutr. 2005, 135, 660S-665S.

53. Bradley, C.K.; Hillman, L.; Sherman, A.R.; Leedy, D.; Cordano, A. Evaluation of two iron-fortified, milk-based formulas during infancy. Pediatrics 1993, 91, 908-914. [PubMed]

54. Yalcin, S.S.; Yurdakok, K.; Acikgoz, D.; Ozmert, E. Short-term developmental outcome of iron prophylaxis in infants. Pediatr. Int. 2000, 42, 625-630. [CrossRef] [PubMed]

55. Engstrom, E.M.; Castro, I.R.; Portela, M.; Cardoso, L.O.; Monteiro, C.A. Effectiveness of daily and weekly iron supplementation in the prevention of anemia in infants. Rev. Saude Publica 2008, 42, 786-795. [CrossRef] [PubMed]

56. Massaga, J.J.; Kitua, A.Y.; Lemnge, M.M.; Akida, J.A.; Malle, L.N.; Ronn, A.M.; Theander, T.G.; Bygbjerg, I.C. Effect of intermittent treatment with amodiaquine on anaemia and malarial fevers in infants in Tanzania: A randomised placebo-controlled trial. Lancet 2003, 361, 1853-1860. [CrossRef]

57. Lind, T.; Lonnerdal, B.; Stenlund, H.; Gamayanti, I.L.; Ismail, D.; Seswandhana, R.; Persson, L.A. A community-based randomized controlled trial of iron and zinc supplementation in Indonesian infants: Effects on growth and development. Am. J. Clin. Nutr. 2004, 80, 729-736. [PubMed]

58. Dewey, K.G.; Domellof, M.; Cohen, R.J.; Landa Rivera, L.; Hernell, O.; Lonnerdal, B. Iron supplementation affects growth and morbidity of breast-fed infants: Results of a randomized trial in Sweden and Honduras. J. Nutr. 2002, 132, 3249-3255. [PubMed] 
59. Caulfield, L.E.; Zavaleta, N.; Figueroa, A. Adding zinc to prenatal iron and folate supplements improves maternal and neonatal zinc status in a Peruvian population. Am. J. Clin. Nutr. 1999, 69, 1257-1263. [PubMed]

60. Prawirohartono, E.P.; Nystrom, L.; Ivarsson, A.; Stenlund, H.; Lind, T. The impact of prenatal vitamin A and zinc supplementation on growth of children up to 2 years of age in rural Java, Indonesia. Public Health Nutr. 2011, 14, 2197-2206. [CrossRef] [PubMed]

61. Castillo-Duran, C.; Marin, V.B.; Alcazar, L.S.; Iturralde, H.; Ruz, M.O. Controlled trial of zinc supplementation in Chilean pregnant adolescents. Nutr. Res. 2001, 21, 715-724. [CrossRef]

62. Mahomed, K.; James, D.K.; Golding, J.; Mccabe, R. Zinc Supplementation during Pregnancy-A Double-Blind Randomized Controlled Trial. Br. Med. J. 1989, 299, 826-830. [CrossRef]

63. Hafeez, A.; Mehmood, G.; Mazhar, F. Oral zinc supplementation in pregnant women and its effect on birth weight: A randomised controlled trial. Arch. Dis. Child. Fetal Neonatal Ed. 2005, 90, 170-171. [CrossRef] [PubMed]

64. Hunt, I.F.; Murphy, N.J.; Cleaver, A.E.; Faraji, B.; Swendseid, M.E.; Browdy, B.L.; Coulson, A.H.; Clark, V.A.; Settlage, R.H.; Smith, J.C. Zinc Supplementation during Pregnancy in Low-Income Teenagers of Mexican Descent-Effects on Selected Blood-Constituents and on Progress and Outcome of Pregnancy. Am. J. Clin. Nutr. 1985, 42, 815-828. [PubMed]

65. Hunt, I.F.; Murphy, N.J.; Cleaver, A.E.; Faraji, B.; Swendseid, M.E.; Coulson, A.H.; Clark, V.A.; Browdy, B.L.; Cabalum, M.T.; Smith, J.C. Zinc Supplementation during Pregnancy-Effects on Selected Blood-Constituents and on Progress and Outcome of Pregnancy in Low-Income Women of Mexican Descent. Am. J. Clin. Nutr. 1984, 40, 508-521. [PubMed]

66. Ross, S.M.; Nel, E.; Naeye, R.L. Differing effects of low and high bulk maternal dietary supplements during pregnancy. Early Hum. Dev. 1985, 10, 295-302. [CrossRef]

67. Prawirohartono, E.P.; Nystrom, L.; Nurdiati, D.S.; Hakimi, M.; Lind, T. The Impact of Prenatal Vitamin A and Zinc Supplementation on Birth Size and Neonatal Survival-A Double-Blind, Randomized Controlled Trial in a Rural Area of Indonesia. Int. J. Vitam. Nutr. Res. 2013, 83, 14-25. [CrossRef] [PubMed]

68. Iannotti, L.L.; Zavaleta, N.; Leon, Z.; Shankar, A.H.; Caulfield, L.E. Maternal zinc supplementation and growth in Peruvian infants. Am. J. Clin. Nutr. 2008, 88, 154-160. [PubMed]

69. Salmenpera, L.; Perheentupa, J.; Nanto, V.; Siimes, M.A. Low Zinc Intake during Exclusive Breast-Feeding Does Not Impair Growth. J. Pediatr. Gastroenterol. Nutr. 1994, 18, 361-370. [CrossRef] [PubMed]

70. Lo, N.B.; Aaron, G.J.; Hess, S.Y.; Dossou, N.I.; Guiro, A.T.; Wade, S.; Brown, K.H. Plasma zinc concentration responds to short-term zinc supplementation, but not zinc fortification, in young children in Senegal. Am. J. Clin. Nutr. 2011, 93, 1348-1355. [CrossRef] [PubMed]

71. Bhandari, N.; Bahl, R.; Taneja, S.; Strand, T.; Molbak, K.; Ulvik, R.J.; Sommerfelt, H.; Bhan, M.K. Substantial reduction in severe diarrheal morbidity by daily zinc supplementation in young north Indian children. Pediatrics 2002, 109, e86. [CrossRef] [PubMed]

72. Bhandari, N.; Taneja, S.; Mazumder, S.; Bahl, R.; Fontaine, O.; Bhan, M.K. Adding zinc to supplemental iron and folic acid does not affect mortality and severe morbidity in young children. J. Nutr. 2007, 137, 112-117. [PubMed]

73. Chang, S.; El Arifeen, S.; Bari, S.; Wahed, M.A.; Rahman, K.M.; Rahman, M.T.; Mahmud, A.B.A.; Begum, N.; Zaman, K.; Baqui, A.H.; Black, R.E. Supplementing iron and zinc: Double blind, randomized evaluation of separate or combined delivery. Eur. J. Clin. Nutr. 2010, 64, 153-160. [CrossRef] [PubMed]

74. Hess, S.Y.; Abbeddou, S.; Jimenez, E.Y.; Some, J.W.; Vosti, S.A.; Ouedraogo, Z.P.; Guissou, R.M.; Ouedraogo, J.B.; Brown, K.H. Small-Quantity Lipid-Based Nutrient Supplements, Regardless of Their Zinc Content, Increase Growth and Reduce the Prevalence of Stunting and Wasting in Young Burkinabe Children: A Cluster-Randomized Trial. PLoS ONE 2015, 10, e0122242. [CrossRef] [PubMed]

75. Mazariegos, M.; Hambidge, K.M.; Westcott, J.E.; Solomons, N.W.; Raboy, V.; Das, A.; Goco, N.; Kindem, M.; Wright, L.L.; Krebs, N.F. Neither a Zinc Supplement nor Phytate-Reduced Maize nor Their Combination Enhance Growth of 6-to 12-Month-Old Guatemalan Infants. J. Nutr. 2010, 140, 1041-1048. [CrossRef] [PubMed]

76. Radhakrishna, K.V.; Hemalatha, R.; Geddam, J.J.B.; Kumar, P.A.; Balakrishna, N.; Shatrugna, V. Effectiveness of Zinc Supplementation to Full Term Normal Infants: A Community Based Double Blind, Randomized, Controlled, Clinical Trial. PLoS ONE 2013, 8, e61486. [CrossRef] [PubMed] 
77. Sazawal, S.; Black, R.E.; Bhan, M.K.; Jalla, S.; Bhandari, N.; Sinha, A.; Majumdar, S. Zinc supplementation reduces the incidence of persistent diarrhea and dysentery among low socioeconomic children in India. J. Nutr. 1996, 126, 443-450. [PubMed]

78. Schlesinger, L.; Arevalo, M.; Arredondo, S.; Diaz, M.; Lonnerdal, B.; Stekel, A. Effect of a Zinc-Fortified Formula on Immunocompetence and Growth of Malnourished Infants. Am. J. Clin. Nutr. 1992, 56, 491-498. [PubMed]

79. Soofi, S.; Cousens, S.; Iqbal, S.P.; Akhund, T.; Khan, J.; Ahmed, I.; Zaidi, A.K.M.; Bhutta, Z.A. Effect of provision of daily zinc and iron with several micronutrients on growth and morbidity among young children in Pakistan: A cluster-randomised trial. Lancet 2013, 382, 29-40. [CrossRef]

80. Surono, I.S.; Martono, P.D.; Kameo, S.; Suradji, E.W.; Koyama, H. Effect of probiotic L. plantarum IS-10506 and zinc supplementation on humoral immune response and zinc status of Indonesian pre-school children. J. Trace Elem. Med. Biol. 2014, 28, 465-469. [CrossRef] [PubMed]

81. Tielsch, J.M.; Khatry, S.K.; Stoltzfus, R.J.; Katz, J.; LeClerq, S.C.; Adhikari, R.; Mullany, L.C.; Black, R.; Shresta, S. Effect of daily zinc supplementation on child mortality in southern Nepal: A community-based, cluster randomised, placebo-controlled trial. Lancet 2007, 370, 1230-1239. [CrossRef]

82. Umeta, M.; West, C.E.; Haidar, J.; Deurenberg, P.; Hautvast, J.G.A.J. Zinc supplementation and stunted infants in Ethiopia: A randomised controlled trial. Lancet 2000, 355, 2021-2026. [CrossRef]

83. Walravens, P.A.; Hambidge, K.M.; Koepfer, D.M. Zinc Supplementation in Infants with a Nutritional Pattern of Failure to Thrive-A Double-Blind, Controlled-Study. Pediatrics 1989, 83, 532-538. [PubMed]

84. Zlotkin, S.; Arthur, P.; Schauer, C.; Antwi, K.Y.; Yeung, G.; Piekarz, A. Home-fortification with iron and zinc sprinkles or iron sprinkles alone successfully treats anemia in infants and young children. J. Nutr. 2003, 133, 1075-1080. [PubMed]

85. Brown, K.H.; de Romana, D.L.; Arsenault, J.E.; Peerson, J.M.; Penny, M.E. Comparison of the effects of zinc delivered in a fortified food or a liquid supplement on the growth, morbidity, and plasma zinc concentrations of young Peruvian children. Am. J. Clin. Nutr. 2007, 85, 538-547. [PubMed]

86. Penny, M.E.; Marin, R.M.; Duran, A.; Peerson, J.M.; Lanata, C.F.; Lonnerdal, B.; Black, R.E.; Brown, K.H. Randomized controlled trial of the effect of daily supplementation with zinc or multiple micronutrients on the morbidity, growth, and micronutrient status of young Peruvian children. Am. J. Clin. Nutr. 2004, 79, 457-465. [PubMed]

87. Wessells, K.R.; Ouedraogo, Z.P.; Rouamba, N.; Hess, S.Y.; Ouedraogo, J.B.; Brown, K.H. Short-term zinc supplementation with dispersible tablets or zinc sulfate solution yields similar positive effects on plasma zinc concentration of young children in Burkina Faso: A randomized controlled trial. J. Pediatr. 2012, 160, 129.e3-135.e3. [CrossRef] [PubMed]

88. Heinig, M.J.; Brown, K.H.; Lonnerdal, B.; Dewey, K.G. Zinc supplementation does not affect growth, morbidity, or motor development of US term breastfed infants at $4-10$ months of age. Am. J. Clin. Nutr. 2006, 84, 594-601. [PubMed]

89. Alarcon, K.; Kolsteren, P.W.; Prada, A.M.; Chian, A.M.; Velarde, R.E.; Pecho, I.L.; Hoeree, T.F. Effects of separate delivery of zinc or zinc and vitamin A on hemoglobin response, growth, and diarrhea in young Peruvian children receiving iron therapy for anemia. Am. J. Clin. Nutr. 2004, 80, 1276-1282. [PubMed]

90. Gardner, J.M.M.; Powell, C.A.; Baker-Henningham, H.; Walker, S.P.; Cole, T.J.; Grantham-McGregor, S.M. Zinc supplementation and psychosocial stimulation: Effects on the development of undernourished Jamaican children. Am. J. Clin. Nutr. 2005, 82, 399-405. [PubMed]

91. Ninh, N.X.; Thissen, J.P.; Collette, L.; Gerard, G.; Khoi, H.H.; Ketelslegers, J.M. Zinc supplementation increases growth and circulating insulin-like growth factor I (IGF-I) in growth-retarded Vietnamese children. Am. J. Clin. Nutr. 1996, 63, 514-519. [PubMed]

92. Rivera, J.A.; Ruel, M.T.; Santizo, M.C.; Lonnerdal, B.; Brown, K.H. Zinc supplementation improves the growth of stunted rural Guatemalan infants. J. Nutr. 1998, 128, 556-562. [PubMed]

93. Sur, D.; Gupta, D.N.; Mondal, S.K.; Ghosh, S.; Manna, B.; Rajendran, K.; Bhattacharya, S.K. Impact of zinc supplementation on diarrheal morbidity and growth pattern of low birth weight infants in Kolkata, India: A randomized, double-blind, placebo-controlled, community-based study. Pediatrics 2003, 112, 1327-1332. [CrossRef] [PubMed]

94. Walravens, P.A.; Chakar, A.; Mokni, R.; Denise, J.; Lemonnier, D. Zinc supplements in breastfed infants. Lancet 1992, 340, 683-685. [CrossRef] 
95. Olney, D.K.; Pollitt, E.; Kariger, P.K.; Khalfan, S.S.; Ali, N.S.; Tielsch, J.M.; Sazawal, S.; Black, R.; Allen, L.H.; Stoltzfus, R.J. Combined iron and folic acid supplementation with or without zinc reduces time to walking unassisted among Zanzibari infants 5-to 11-month old. J. Nutr. 2006, 136, 2427-2434. [PubMed]

96. Umeta, M.; West, C.E.; Verhoef, H.; Haidar, J.; Hautvast, J.G.A.J. Factors associated with stunting in infants aged 5-11 months in the Dodota-Sire District, rural Ethiopia. J. Nutr. 2003, 133, 1064-1069. [PubMed]

97. Wuehler, S.E.; Sempertegui, F.; Brown, K.H. Dose-response trial of prophylactic zinc supplements, with or without copper, in young Ecuadorian children at risk of zinc deficiency. Am. J. Clin. Nutr. 2008, 87, 723-733. [PubMed]

98. Sazawal, S.; Black, R.E.; Bhan, M.K.; Jalla, S.; Sinha, A.; Bhandari, N. Efficacy of zinc supplementation in reducing the incidence and prevalence of acute diarrhea-A community-based, double-blind, controlled trial. Am. J. Clin. Nutr. 1997, 66, 413-418. [PubMed]

99. Tielsch, J.M.; Khatry, S.K.; Stoltzfus, R.J.; Katz, J.; LeClerq, S.C.; Adhikari, R.; Mullany, L.C.; Shresta, S.; Black, R.E. Effect of routine prophylactic supplementation with iron and folic acid on preschool child mortality in southern Nepal: Community-based, cluster-randomised, placebo-controlled trial. Lancet 2006, 367, 144-152. [CrossRef]

100. Larson, C.P.; Nasrin, D.; Saha, A.; Chowdhury, M.I.; Qadri, F. The added benefit of zinc supplementation after zinc treatment of acute childhood diarrhoea: A randomized, double-blind field trial. Trop. Med. Int. Health 2010, 15, 754-761. [CrossRef] [PubMed]

101. Gupta, D.N.; Mondal, S.K.; Ghosh, S.; Rajendran, K.; Sur, D.; Manna, B. Impact of zinc supplementation on diarrhoeal morbidity in rural children of West Bengal, India. Acta Paediatr. 2003, 92, 531-536. [CrossRef] [PubMed]

102. Ruel, M.T.; Rivera, J.A.; Santizo, M.C.; Lonnerdal, B.; Brown, K.H. Impact of zinc supplementation on morbidity from diarrhea and respiratory infections among rural Guatemalan children. Pediatrics 1997, 99, 808-813. [CrossRef] [PubMed]

103. Chhagan, M.K.; Van den Broeck, J.; Luabeya, K.K.; Mpontshane, N.; Tucker, K.L.; Bennish, M.L. Effect of micronutrient supplementation on diarrhoeal disease among stunted children in rural South Africa. Eur. J. Clin. Nutr. 2009, 63, 850-857. [CrossRef] [PubMed]

104. Sazawal, S. Daily zinc supplements reduced the incidence and severity of acute lower respiratory infections in children in India. Evid. Based Nurs. 1999, 2, 12.

105. Ramakrishnan, U.; Gonzalez-Cossio, T.; Neufeld, L.M.; Rivera, J.; Martorell, R. Multiple micronutrient supplementation during pregnancy does not lead to greater infant birth size than does iron-only supplementation: A randomized controlled trial in a semirural community in Mexico. Am. J. Clin. Nutr. 2003, 77, 720-725. [PubMed]

106. Taneja, S.; Bhandari, N.; Bahl, R.; Bhan, M.K. Impact of zinc supplementation on mental and psychomotor scores of children aged 12 to 18 months: A randomized, double-blind trial. J. Pediatr. 2005, 146, 506-511. [CrossRef] [PubMed]

107. Castillo-Duran, C.; Perales, C.G.; Hertrampf, E.D.; Marin, V.B.; Rivera, F.A.; Icaza, G. Effect of zinc supplementation on development and growth of Chilean infants. J. Pediatr. 2001, 138, 229-235. [CrossRef] [PubMed]

108. Ota, E.; Mori, R.; Middleton, P.; Tobe-Gai, R.; Mahomed, K.; Miyazaki, C.; Bhutta, Z.A. Zinc supplementation for improving pregnancy and infant outcome. Cochrane Database Syst. Rev. 2015, 2, CD000230.

109. Chaffee, B.W.; King, J.C. Effect of Zinc Supplementation on Pregnancy and Infant Outcomes: A Systematic Review. Paediatr. Perinat. Epidemiol. 2012, 26, 118-137. [CrossRef] [PubMed]

110. Pena-Rosas, J.P.; De-Regil, L.M.; Garcia-Casal, M.N.; Dowswell, T. Daily oral iron supplementation during pregnancy. Cochrane Database Syst. Rev. 2015, 7, CD004736.

111. Eichler, K.; Wieser, S.; Ruthemann, I.; Brugger, U. Effects of micronutrient fortified milk and cereal food for infants and children: A systematic review. BMC Public Health 2012, 12, 506. [CrossRef] [PubMed]

112. Pasricha, S.R.; Hayes, E.; Kalumba, K.; Biggs, B.A. Effect of daily iron supplementation on health in children aged 4-23 months: A systematic review and meta-analysis of randomised controlled trials. Lancet Glob. Health 2013, 1, E77-E86. [CrossRef]

113. Cook, J.D.; Lipschit, D.A.; Miles, L.E.M.; Finch, C.A. Serum Ferritin as a Measure of Iron Stores in Normal Subjects. Am. J. Clin. Nutr. 1974, 27, 681-687. [PubMed] 
114. Moretti, D.; Zimmermann, M.B.; Wegmuller, R.; Walczyk, T.; Zeder, C.; Hurrell, R.F. Iron status and food matrix strongly affect the relative bioavailability of ferric pyrophosphate in humans. Am. J. Clin. Nutr. 2006, 83, 632-638. [PubMed]

115. Petry, N.; Olofin, I.; Hurrell, R.F.; Boy, E.; Wirth, J.P.; Moursi, M.; Donahue Angel, M.; Rohner, F. The Proportion of Anemia Associated with Iron Deficiency in Low, Medium, and High Human Development Index Countries: A Systematic Analysis of National Surveys. Nutrients 2016, 8. [CrossRef] [PubMed]

116. De Brito, N.J.; Rocha, E.D.; de Araujo Silva, A.; Costa, J.B.; Franca, M.C.; das Gracas Almeida, M.; Brandao-Neto, J. Oral zinc supplementation decreases the serum iron concentration in healthy schoolchildren: A pilot study. Nutrients 2014, 6, 3460-3473. [CrossRef] [PubMed]

117. Cook, J.D.; Dassenko, S.A.; Lynch, S.R. Assessment of the role of nonheme-iron availability in iron balance. Am. J. Clin. Nutr. 1991, 54, 717-722. [PubMed]

118. Reddy, M.B.; Hurrell, R.F.; Cook, J.D. Estimation of nonheme-iron bioavailability from meal composition. Am. J. Clin. Nutr. 2000, 71, 937-943. [PubMed]

119. Singla, P.N.; Tyagi, M.; Shankar, R.; Dash, D.; Kumar, A. Fetal iron status in maternal anemia. Acta Paediatr. 1996, 85, 1327-1330. [CrossRef] [PubMed]

120. Beard, J. Iron deficiency alters brain development and functioning. J. Nutr. 2003, 133, 1468S-1472S. [PubMed]

121. Nakamori, M.; Ninh, N.X.; Isomura, H.; Yoshiike, N.; Hien, V.T.; Nhug, B.T.; Nhien, N.V.; Nakano, T.; Khan, N.C.; Yamamoto, S. Nutritional status of lactating mothers and their breast milk concentration of iron, zinc and copper in rural Vietnam. J. Nutr. Sci. Vitaminol. (Tokyo) 2009, 55, 338-345. [CrossRef] [PubMed]

122. Mahdavi, R.; Nikniaz, L.; Gayemmagami, S.J. Association between Zinc, Copper, and Iron Concentrations in Breast Milk and Growth of Healthy Infants in Tabriz, Iran. Biol. Trace Elem. Res. 2010, 135, 174-181. [CrossRef] [PubMed]

123. Domellof, M.; Lonnerdal, B.; Dewey, K.G.; Cohen, R.J.; Hernell, O. Iron, zinc, and copper concentrations in breast milk are independent of maternal mineral status. Am. J. Clin. Nutr. 2004, 79, 111-115. [PubMed]

124. Shashiraj; Faridi, M.M.A.; Singh, O.; Rusia, U. Mother's iron status, breastmilk iron and lactoferrin-Are they related? Eur. J. Clin. Nutr. 2006, 60, 903-908. [CrossRef] [PubMed]

(C) 2016 by the authors; licensee MDPI, Basel, Switzerland. This article is an open access article distributed under the terms and conditions of the Creative Commons Attribution (CC-BY) license (http://creativecommons.org/licenses/by/4.0/). 